NBER WORKING PAPER SERIES

\title{
THE GEOGRAPHY AND CHANNELS OF DIFFUSION AT THE WORLD'S TECHNOLOGY FRONTIER
}

\author{
Wolfgang Keller \\ Working Paper 8150 \\ http://www.nber.org/papers/w8150 \\ NATIONAL BUREAU OF ECONOMIC RESEARCH \\ 1050 Massachusetts Avenue \\ Cambridge, MA 02138 \\ March 2001
}

Thanks to Peter Debaere, Robert Feenstra, Dan Hamermesh, Jim Harrigan, Gianmarco Ottaviano, and Jim Tybout, as well as seminar participants at the Econometric Society North America Winter 200 Meetings, the Hamburg Institute of International Economics, LSE, the NBER Summer Institute 2000, and the University of Texas for comments, and Kim Figueira of Statistics Canada for help with the Canadian language data. This work has been supported by the National Science Foundation under grant number SES-98 8902. I also thank Anne Golla and Dong Li for research assistance. The views expressed herein are those of the author and not necessarily those of the National Bureau of Economic Research.

(C) 2001 by Wolfgang Keller. All rights reserved. Short sections of text, not to exceed two paragraphs, may be quoted without explicit permission provided that full credit, including $\mathbb{C}$ notice, is given to the source. 
The Geography and Channels of Diffusion at the World's Technology Frontier Wolfgang Keller NBER Working Paper No. 8150

March 2001

JEL No. O3, F2

\begin{abstract}
Convergence in per capita income turns on whether technological knowledge spillovers are global or local. Global spillovers favor convergence, while a geographically limited scope of knowledge diffusion can lead to regional clusters of countries with persistently different levels of income per capita. This paper estimates the importance of geographic distance for technology diffusion, how this changed over time, and whether international trade, foreign direct investment, and communication flows serve as important channels of diffusion. The analysis is based on examining the productivity effects of R\&D expenditures in the world's seven major industrialized countries between 1970 and 1995. First, I find that the scope of technology diffusion is severely limited by distance: the geographic half-life of technology, the distance at which half of the technology has disappeared, is estimated to be only 1,200 kilometers. Second, technological knowledge has become a lot more global from the early 1970s to the 1990s. Third, I estimate that trade patterns account for the majority of all differences in bilateral technology diffusion, whereas foreign direct investment and language skills differences contribute circa 15\% each. Lastly, these three channels together account for almost the entire localization effect that would otherwise be attributed to geographic distance.
\end{abstract}

Wolfgang Keller Department of Economics University of Texas

BRB 3.152

Austin, Texas 78712

and NBER

keller@eco.utexas.edu 
Convergence in per capita income depends on the degree of international technology diffusion. Strong diffusion of technological knowledge favors convergence, while the absence of it can lead to divergence if the domestic rate of technological change varies across countries. A case in point is the faster implementation of recent advances in information technology in the United States (U.S.) compared to other countries. This has been cited as major reason of why the U.S.'s lead in per capita income over Japan has increased from $10 \%$ in 1990 to $20 \%$ by 1999 (e.g., McKinsey 2000, Economist 2000). The scope of technology diffusion also matters for income convergence among the world's advanced ("North") and less developed countries ("South"). For instance, the issue is widely discussed in the context of the "digital divide" scenario-the widespread fear that the internet might not lead to convergence, but instead to a further polarization of per capita income in the world.

This paper studies international technology diffusion among the world's seven major industrialized countries on a geographic basis. It is well-known, for instance, that foreign direct investment (FDI) patterns are affected by spatial factors, and it is a stylized fact that the volume of bilateral trade declines with distance (e.g., Caves 1996, Leamer and Levinsohn 1995, respectively). Because trade and FDI patterns might determine a country's access to embodied foreign technology in form of advanced intermediate goods, these mechanisms are both plausible channels of technological diffusion. ${ }^{1}$ Disembodied technology diffusion in form of direct communication could be another major way of how technological knowledge moves between countries, and while distance affects the likelihood of face-to-face interactions, it matters much less for communication via telephone or email. ${ }^{2}$ Rather, language and other cultural-historic factors play a relatively larger role for communication flows than for trade or FDI. At this time however, relatively little is known on how geographic and other factors impact technology diffusion among countries.

\footnotetext{
${ }^{1}$ There are other ways through which FDI and trade might affect technology diffusion; see e.g. the discussion of FDI in Blomstrom and Kokko (1996).

${ }^{2}$ For an analysis of the continuing importance of face-to-face interactions, though, see Gaspar and Glaeser (1996).
} 
My empirical analysis will first address the question whether geographic distance affects the degree of diffusion. In particular, do remotely located countries have a smaller stock of technological knowledge at their disposal than more centrally located countries? Second, I will study whether this relationship has changed over time. The analysis has major implications for economic policies towards growth and innovation, because if technological knowledge diffuses fully as well as quickly, such policies cannot raise a country's relative welfare. Third, I will examine whether trade, FDI, and communication matter as specific channels of technology diffusion. Going beyond the analysis of distance is important, because economic policy might be powerful in affecting trade, FDI, or communication patterns, whereas it cannot, at least literally, affect a country's geographic location relative to other countries.

This paper builds on a substantial amount of work showing that the link between the research and development $(\mathrm{R} \& \mathrm{D})$ spending in one industry and productivity in another is best viewed as a process of technology diffusion (Scherer 1984, Griliches 1995). It is based on data for two- and three-digit manufacturing industries in Canada, France, Germany, Italy, Japan, the United Kingdom (U.K.), and the U.S.--the so-called G-7 countries- during the years of 1970 to 1995. The G-7 countries account for more than $90 \%$ of the world's R\&D spending, and also by most other measures, these countries are among the technologically most-advanced in the world. I refer thus to the G-7 countries collectively as the world's technology frontier.

Recent contributions showing that strong technology diffusion favors convergence while divergence is likely if technological knowledge remains local include Feenstra (1996) and Grossman and Helpman (1991). In the empirical literature, Eaton and Kortum $(1999,1996)$ estimate models of technology diffusion and productivity growth. The Eaton and Kortum (1996) estimates from an equation of patenting activity suggest that technology diffusion declines with geographic distance, a finding that is primarily identified from variation of within- versus across-country patenting. Jaffe, Trajtenberg, 
and Henderson (1993) also emphasize that technology diffusion is affected by country borders by showing that U.S. patents are more likely to be cited by other U.S. patents than by foreign patents. ${ }^{3}$ In contrast, Sjöholm (1996) finds that geographic distance does not significantly influence the number of patent citations to the research output of a sample of Swedish firms.

Other work has studied international technology spillovers by relating R\&D to productivity in a production function framework (e.g., Coe and Helpman 1995). This literature often focuses on trade as the primary mechanism of technology diffusion. However, if there are strong regional effects that are unrelated to trade, or a number of channels of technology diffusion are at work simultaneously, this could be problematic. ${ }^{4}$ Moreover, the earlier literature distinguishes only between domestic and foreign sources of $R \& D$, whereas here I exploit cross-sectional variation in the relative distance of countries to their partner countries. In contrast to this paper, Keller (2000b) focuses on technology diffusion from the technological frontier to other countries.

This paper also relates to recent work in international trade which has established that technology differences across countries are important in explaining the comparative advantage and trade of countries (e.g., Trefler 1995). Thus, a better understanding of technology diffusion will help to explain the pattern and volume of international trade, and eventually, both how trade acts as a channel of technology diffusion and how in turn the resulting differences in production technologies shape international trade. Moreover, the analysis of embodied and disembodied forms of international technology diffusion in this paper is relevant for the recent debate in macroeconomics that tries to determine the degree to which technical change is disembodied rather than embodied in capital goods. ${ }^{5}$

\footnotetext{
${ }^{3}$ See also Branstetter (2001) who shows that intranational spillovers in the U.S. and Japan are larger than spillovers between these countries, as well as Jaffe and Trajtenberg (2000) who examine knowledge flows using international patent citation data.

${ }^{4}$ For instance, Eaton and Kortum (1996) find a role for both geographic distance and trade in technology diffusion; see also the analysis in Keller (1998, 2000a).

${ }^{5}$ See, e.g., Hulten (1992), Greenwood, Hercowitz, and Krusell (1997), and the open-economy analysis by Eaton and Kortum (2000).
} 
By seeking to explain patterns of agglomeration and de-agglomeration through spatial trade externalities, work in regional and urban economics such as Fujita, Krugman, and Venables (1999) has had a similar focus recently as the trade and growth literature. In particular, Baldwin and Forslid's (2000) model incorporates both technology spillovers and trade externalities, showing that while more technology spillovers favors income convergence, a lower level of transport costs for trade might lead to divergence. Empirical work in this area includes Hanson (1998) as well as Redding and Venables (2000). And even though this paper focuses on the world's technology frontier, the role of geography in economic development has recently also been emphasized for poorer nations (see, e.g., Gallup, Sachs, and Mellinger 1998).

I note as a caveat that while the following empirical analysis of the geography and channels of technology diffusion gives some important insights, it cannot provide a complete picture of how these factors matter. Geographic factors by themselves are not a good economic explanation, and the impact of geography on trade, FDI, or direct communication, as well as the resulting levels of technology diffusion will eventually have to be modelled explicitly. It is hoped that this analysis of geography and specific channels of diffusion will be an important input for future modelling and estimation by shedding additional light on which mechanisms are particularly important.

The remainder of the paper is as follows. The next section provides an overview of the data. Important econometric issues raised by the estimations are addressed in part two. All estimation results and the discussion of their economic significance can be found in section three. Section four concludes with a general assessment of the results and notes a number of issues that will have to be addressed in the future. 


\section{Empirical setting}

This section examines the data in some detail, providing a context that shows how R\&D expenditures, productivity, geography, as well as trade, FDI, and communication links in the sample vary.

\subsection{Major country and industry characteristics in terms of GDP and R\&D}

I use data on manufacturing industries in Canada, France, Germany, Italy, Japan, the United Kingdom (U.K.), and the United States (U.S.) for the years 1970-1995. All countries are members of the Organization for Economic Co-operation and Development (OECD), and the OECD STAN database is the primary source for the data on inputs, outputs, and prices (OECD 1999a). Manufacturing industries in these seven countries account for about 16\% of world GDP and approximately two thirds of world GDP in manufacturing in 1980. Moreover, these countries account for the majority of R\&D expenditures in the world: ninety-four percent of all business enterprise R\&D that is recorded in OECD statistics is conducted in the G-7 countries (source: OECD 1998). ${ }^{6}$

The analysis encompasses almost all of manufacturing, subdivided into twelve industries at the two- to three-digit International Standard Industrial Classification (ISIC) level. ${ }^{7}$ These are food, beverages and tobacco (ISIC 31), textiles, apparel, and leather (ISIC 32), wood products and furniture (ISIC 33), paper and printing (ISIC 34), chemicals and drugs (ISIC 351+352), rubber and plastics (ISIC 355+356), non-metallic mineral products (ISIC 36), basic metals (ISIC 37), metal products (ISIC 381), non-electrical machinery and instruments (ISIC 382+385), electrical machinery (ISIC 383), and transportation equipment (ISIC 384). Table 1 provides summary statistics on the relative size of the countries and industries. The size of the countries varies substantially in terms

\footnotetext{
${ }^{6}$ The remainder of $6 \%$ is R\&D in the Netherlands, Sweden, South Korea, and other countries. After the R\&D expenditures in non-OECD countries are taken into account, it is plausible to assume that the G-7 countries conduct at least $90 \%$ of all business enterprise $\mathrm{R} \& \mathrm{D}$ in the world.

${ }^{7}$ Two industries have been dropped from the sample: ISIC 353+354, Petroleum and Refineries, because of less reliable data, and ISIC 39, Other Manufacturing, because it includes rather different products across countries.
} 
of GDP. Canada's share of G-7 manufacturing is 3.15\%, while the U.S. contributes 33.62\%. By industry, food manufacturing is largest in the G-7 countries, but also transportation equipment as well as non-electrical machinery and instruments are industries that have a share of more than $10 \%$ of manufacturing. In terms of $\mathrm{R} \& \mathrm{D}$, country size varies even more, see the middle columns in Table 1. The U.S. conducts circa forty times as much R\&D as Canada, and about four times as much as Germany. Japan spends about half as much on R\&D as does the United States. Also in the industry dimension, $R \& D$ expenditures are more concentrated than GDP is. Most of the $R \& D$ is done in chemicals, machinery, electronics, and transportation, accounting for a total of almost $90 \%$ of all R\&D in manufacturing.

The R\&D expenditure flows are transformed into stocks with the perpetual inventory method (see Appendix A for details). Table 1, on the right, shows that the average annual growth rates of R\&D stocks vary substantially by country, from a high of $11.82 \%$ for Germany to a low of $5.72 \%$ for the United Kingdom. Average R\&D stock growth for the U.S. has been $7.36 \%$ per year.

\subsection{Geographic features of the sample}

The geographic distance between countries is measured as the smallest arc tan distance between the capital cities of the countries, as the crow flies (source: Haveman 1998). Table 2.1 allows to distinguish several groups of countries: the European G-7 countries, which are about 6,000 kilometers from the U.S. and Canada and 9,500 kilometers from Japan, while the latter is about 10,500 kilometers from Canada and the United States. In consequence, the countries' average distance to their six partner countries varies substantially: for the four European countries, it is around 4,000 kilometers, for the U.S. and Canada, it is about 6,000 kilometer, and for the relatively isolated Japan, it is close to 10,000 kilometers. 


\subsection{Bilateral Trade and Foreign Direct Investment Patterns and Data on Lan- guage Skills}

The data on bilateral language skills, FDI, and trade is shown in Tables 2.2 to 2.4. The source for the bilateral import shares in Table 2.2 is the NBER's Bilateral World Trade Database, see Feenstra, Lipsey, and Bowen (1997). The FDI data come primarily from the OECD's Activities of Foreign Affiliates, OECD (1999c). Table 2.3 shows the share of employment of the outward FDI country in the total manufacturing employment of the host country. For instance, line 2 in Table 2.3 indicates that German-owned multinationals account for $2.40 \%$ of manufacturing employment in France, while the share of U.S.-owned multinationals in France is, with $4.72 \%$, about twice as large.

A number of considerations suggest to use caution in interpreting the results based on these numbers. First, mainly due to availability reasons, the data I use is at the aggregate, not at the industry level. ${ }^{8}$ While this implies losing the industry detail, it also means that these variables are employed on par with distance, which does not have an industry dimension either. Second, each set of bilateral relations is only for one year that is relatively late in or after the sample period. ${ }^{9}$ This could mean that simultaneity afflicts the estimation results, because, e.g., changes in productivity influence the patterns of trade just as trade leads to embodied technology diffusion. However, the bilateral patterns are slow-changing over time, and the fact that the values are for total manufacturing (in the case of trade and FDI) or the country as a whole (in the case of language skills, see below) suggests that simultaneity is unlikely to be a major problem. ${ }^{10}$

The data on language skills in Table 2.4 shows the share of the population in the technology recipient country that speaks the official language of the sender country. For instance, line 3 in Table 2.4 states that $41 \%$ of the population in Germany speaks English, while only $11 \%$ speaks

\footnotetext{
${ }^{8}$ Trade shares could be obtained at the industry level, though; see e.g. the analysis in Keller (2000a).

${ }^{9}$ For FDI and import patterns, this is the year 1991, while for language skill data, it is 1996/1998.

${ }^{10} \mathrm{I}$ have confirmed this by using trade data for years other than 1991, which leads to similar results.
} 
French. ${ }^{11}$ Both due to estimation of some of the data and for conceptual reasons, the inferences that can be made based on the language skills results below are those associated with the highest level of uncertainty. Conceptually, language knowledge in the population might be a poor indicator for the strength of communication links fostering technology diffusion among firms in two- to three-digit manufacturing industries. Moreover, bilateral language knowledge, for instance, the share of people in Italy that is able to speak German, might be of limited relevance for understanding disembodied bilateral diffusion from Germany to Italy if communication is typically conducted in a third-country language, such as English. However, the analysis in West, Edge, and Stokes (2000) suggests that language knowledge in the population is correlated with business-relevant language skills. In addition, the evidence on changes in language skills over time in EU (1999) and other evidence indicates that the degree of coordination on one or a small number of languages is still limited. Overall, this suggests that this data on language skills will be useful in studying the importance of communication flows for bilateral technology diffusion.

\subsection{Multi-lateral total factor productivity indices}

I will compare industry-level total factor productivity (TFP) for the seven countries in the sample. ${ }^{12}$ TFP calculations require real, internationally comparable data on outputs, inputs, and intermediate goods. The OECD STAN database contains estimates of value added, labor, and capital inputs, which I have used to construct TFP indices. The intermediate inputs data on which the value added series are based is not fully internationally comparable, which is one important reason of why the

\footnotetext{
${ }^{11}$ In the case of Canada, I simplify by taking English as the sole official language. The data for the European countries comes from EU (1999) and the data for Canada comes from StatCan (2000). The EU (1999) survey asked the following question: "Which languages can you speak well enough to take part in a conversation, apart from your mother tongue?". To arrive at the estimates for language knowledge in the U.S. and Japan, I have used information on foreign nationals in these countries, in particular for Japan from JG (2000). I have confirmed that the results are not sensitive to employing other plausible values for these data series.

${ }^{12}$ More details on the TFP index construction can be found in Appendix B. Other recent work that has examined TFP indices for other purposes includes Harrigan (1997) and Griffith, Redding, and van Reenen (2000).
} 
TFP indices in this paper should be viewed as approximations to the true TFP measures. ${ }^{13}$ I use the multi-lateral TFP index proposed by Caves, Christensen, and Diewert (1982a), which is defined as

$$
\ln F_{c i t}=\left(\ln Z_{c i t}-\overline{\ln Z_{i t}}\right)-\bar{\sigma}_{c i t}\left(\ln L_{c i t}-\overline{\ln L_{i t}}\right)-\left(1-\bar{\sigma}_{c i t}\right)\left(\ln K_{c i t}-\overline{\ln K_{i t}}\right), \forall c, i, t
$$

where $c=1, \ldots, C ; i=1, \ldots, I ; t=1, \ldots, T ; c$ indexes country, $i$ indexes industry, and $t$ is the subscript for time. The variable $Z$ is value-added, $L$ is labor inputs, and $K$ denotes capital inputs. Further, $\overline{\ln Z_{i t}}$ is given by $\overline{\ln Z_{i t}}=\frac{1}{C} \sum_{c} \ln Z_{c i t}$; correspondingly, $\overline{\ln L_{i t}}=\frac{1}{C} \sum_{c} \ln L_{c i t}$ and $\overline{\ln K_{i t}}=$ $\frac{1}{C} \sum_{c} \ln K_{c i t}$. The variable $\bar{\sigma}_{c i t}$ is an average of labor cost shares, $\bar{\sigma}_{c i t}=\frac{1}{2}\left(\alpha_{c i t}+\bar{\alpha}_{i t}\right)$, where $\alpha_{c i t}, \forall c, i, t$, is the cost share of labor, and $\bar{\alpha}_{i t}$ is its country average, $\bar{\alpha}_{i t}=\frac{1}{C} \sum_{c} \alpha_{c i t}$. This TFP index is superlative in the sense that it is exact for the flexible translog functional form. It is also transitive, so that the choice of the base country does not matter. In equation (1), the reference point is the geometric average of the seven countries.

The TFP index in equation (1) assumes that production is characterized by constant returns to scale. Building on the work by Caves, Christensen, and Diewert (1982b) and Hall (1990), I have also used cost-based instead of revenue-based factor shares to construct alternative TFP indices that are appropriate in the presence of scale economies. This allows me to see whether the estimation results are robust to deviations from the assumption of constant returns. Two other important characteristics of the TFP data are: First, industry-specific purchasing power parity- (PPP) exchange rate estimates are used to convert the industry outputs into a common currency, because there is evidence that PPP exchange rates vary substantially by industry (source: Pilat 1996). ${ }^{14}$ Second, I have adjusted the OECD STAN data on labor inputs to take account for differences in annual hours worked across countries, from OECD (1999b). This is important because annual hours worked

\footnotetext{
${ }^{13}$ As a robustness check I also report results based on TFP indices that are constructed with data on gross output (i.e., where intermediate inputs have not been netted out).

${ }^{14}$ All-manufacturing PPP exchange rates from OECD (1999a) are also employed as a robustness check.
} 
in U.S. manufacturing, for example, were almost $40 \%$ higher than in certain European countries in some years over the sample period. I have also corrected the physical capital inputs series to account for cyclical determinants of factor demand. Figure 1 shows the adjusted and non-adjusted average productivity levels for the U.S. (on top), Germany (middle), and Japan (bottom), relative to the G-7 mean for each year. ${ }^{15}$ Without adjusting for differences in input usage, U.S. productivity would be increasingly over- and German productivity increasingly under-estimated, while productivity in Japan would be overestimated throughout. Clearly, these differences would not be appropriately controlled for by using time-invariant country fixed-effects.

\subsubsection{Industry-level productivity and average productivity over time}

There is a substantial amount of within-country heterogeneity across industries. For instance, a country is frequently among the top performers in one industry while ranking near the bottom in another industry. This suggests that studying productivity at the industry level might have important advantages compared to an analysis at a more aggregate level. There are also differences of how variation in with-in country productivity levels has changed over time. For instance, in the U.S., the dispersion of productivity levels has fallen, whereas in Canada, the opposite has occurred.. For the G-7 countries as a whole, a picture of slightly converging within-country productivity levels emerges, as indicated by the dashed line in Figure 2 .

On average across industries, the U.S. has been the productivity leader throughout most of the sample period according to these estimates, even though the U.S.'s productivity advantage has generally been shrinking over time. ${ }^{16}$ The solid line in Figure 2, which is more substantially downwardsloping, shows the standard deviation of the seven country averages of productivity over time. Clearly,

\footnotetext{
${ }^{15}$ These are unweighted averages across industries. Size-weighted averages behave similar.

${ }^{16}$ Canada started out in second place in 1970, but has lost ground since, especially to Italy and France. Relative productivity in Germany was rising until about 1980 but fell subsequently, and by 1995 German productivity is approximately equal to the mean in the sample. In Japan and the U.K., productivity was below the sample average throughout the sample period according to my estimates.
} 
the period of 1970-95 has been one of productivity convergence among the G-7 countries, albeit with a noticeable reversal towards divergence since the year 1990. These findings are consistent with a relatively high degree of technology diffusion among the countries at the world's technology frontier. However, if the trend towards productivity divergence after 1990 will be sustained, this could mean that the number of countries at the world's technology frontier will be smaller in the future than it is today. ${ }^{17}$

To investigate this further I will now turn to the formal econometric analysis.

\section{Estimation equation and econometric issues}

Geographic factors might affect the degree of technology diffusion for various reasons. For instance, according to many trade-and-growth models, technology moves across country borders when intermediate goods embodying new technological knowledge are traded (see, e.g., Grossman and Helpman 1991). It is plausible to assume that it is easier to ship technology-carrying intermediate goods to near-by locations than to more remote locations, so that the scope of technology diffusion is related to geographic distance. ${ }^{18}$ The equilibrium in these models typically relates productivity in an importing country both to domestic $\mathrm{R} \& \mathrm{D}$ and to foreign $\mathrm{R} \& \mathrm{D}$, conditional on bilateral distance. A specification that captures this is

$$
\ln F_{c i t}=\alpha_{c i}+\alpha_{t}+\beta \ln \left[S_{c i t}+\sum_{g \neq c} \gamma S_{g i t} e^{-\delta D_{c g}}\right]+\varepsilon_{c i t}, \forall c, i, t,
$$

\footnotetext{
${ }^{17}$ One reason for this trend towards divergence is that the U.S. is increasing its productivity lead over the other countries. It might be in part due to measurement issues, in particular the differential treatment of information technology (IT) price indices (IT includes computers). IT equipment prices have fallen much more rapidly in the U.S. than in other countries according to official numbers. This is largely due to the usage of hedonic price indices in the U.S., whereas other sample countries continue to use non-hedonic price deflators; see Scarpetta, Bassanini, Pilat, and Schreyer (2000). The extent to which this affects the estimation results below is limited, however, which is likely due to the fixed effects that are included in the specification; see section 2 below.

${ }^{18}$ The relationship can be formalized by assuming that commodity trade entails transport costs that are increasing with geographic distance (as in Samuelson 1954).
} 
where $c=1, \ldots, C$ indexes country, $i=1, \ldots, I$ is an index for industry, and $t=1, \ldots, T$ is the subscript for time. The variable $F_{c i t}$ is the TFP level, $S_{c i t}$ is country c's R\&D stock, and $D_{c g}$ is the geographic distance between countries $c$ and $g$. The $\alpha_{c i}, \alpha_{t}, \beta, \gamma$, and $\delta$ are parameters to be estimated, and $\varepsilon_{c i t}$ is an error term with properties that I discuss below. The $\alpha$ 's are fixed effects that control for unobserved heterogeneity, the parameter $\beta$ measures the effect of R\&D on productivity, while $\gamma$ captures the relative effect from foreign R\&D. ${ }^{19}$

The role of geographic distance is captured by the parameter $\delta$, which I will refer to as the distance parameter. It is identified from variation of the productivity effects of $R \& D$ in other countries conditional on bilateral distance, and thus reveals whether there is a geographic dimension to international technology diffusion. Denote the term $S_{g} e^{-\delta D_{c g}}$ as country c's effective R\&D from country $g$; positive estimates of $\delta$ mean that variation in productivity levels can be better explained by assuming that effective $R \& D$ from countries located relatively far away is smaller than that of other countries located more closely. For positive values of $\gamma$ (foreign $R \& D$ raises productivity), estimating $\delta>0$ suggests that the benefits from foreign technology creation are decreasing with geographic distance. In contrast, $\delta<0$ would mean that distant countries benefit more from a given country's R\&D than near-by countries.

I will also present results based on a distance class specification that does not incorporate the exponential functional form. It is given by

$$
\ln F_{c i t}=\alpha_{c i}+\alpha_{t}+\beta \ln \left[S_{c i t}+\sum_{g \neq c} \gamma\left(1+\eta I_{c g}\right) S_{g i t}\right]+\varepsilon_{c i t}, \forall c, i, t
$$

where $I_{c g}=0$ if countries $c$ and $g$ are between 2,000 and 7,500 kilometers apart; $I_{c g}=1$ for distances

\footnotetext{
${ }^{19}$ The parameter $\beta$ captures both 'true' knowledge spillovers as well as measurement spillovers. The latter do not constitute an externality, as they might be due only to price indices that do not perfectly adjust for product quality, for example (see Griliches 1995 for a discussion). The estimates should therefore be treated as an upper bound for the magnitude of true external effects.
} 
below 2, 000 kilometers, and $I_{c g}=-1$ for distances above 7,500 kilometers. The distance parameter $\eta$ identifies the higher (lower) effect of $\mathrm{R} \& \mathrm{D}$ among bilateral relationships of less than 2,000 (more than 7,500$)$ kilometers, compared to the relative effect of foreign $\mathrm{R} \& \mathrm{D}$ of $\gamma$ when $I_{c g}$ is equal to 0 . Positive estimates of $\eta$ are consistent with less technology diffusion as bilateral distance increases. ${ }^{20}$ I will also augment the specifications (2) and (3) in simple ways to examine whether the distance parameters $\delta$ and $\eta$ have changed over time. This would suggest a more or less localized pool of technology among the G-7 countries. Moreover, to analyze the specific channels of trade, FDI, and communication, I will modify equation (2 ) to include bilateral trade and FDI patterns as well as language skills data in ways that are analogous to the distance variable.

Major estimation issues that need to be addressed are as follows. First, the relatively narrow focus on the countries at the world's technology frontier implies that the number of bilateral relations is small, with only $C(C-1)=42$, and half as many values for bilateral distance. Moreover, four countries are located in Europe and two in North America, so that the qualitatively distinct ranges that $D_{c g}$ falls into is even more limited. This is part of what motivates the distance class analysis. In contrast to distance, there is no symmetry in the import, FDI, and language skill patterns, but generally, the relatively small number of bilateral relations will likely affect the precision with which the parameters can be estimated.

Another concern is that the error term $\varepsilon_{c i t}$ is not orthogonal to the regressors, because this would lead to inconsistent estimates. The disturbances capture idiosyncratic factors that affect measured productivity. Some could be industry-specific, such as receiving strong inter-industry spillovers, and others might be common to all industries in a given country, such as shocks affecting the national business cycle. Generally, this calls for instrumental-variable estimation; however, good instruments

\footnotetext{
${ }^{20}$ This higher and lower effect relative to distance class $I_{c g}=0$ need not be symmetric, as is assumed here; in the estimations below, however, the gain in empirical fit through allowing for an asymmetric effect is very small.
} 
for the R\&D variables are unavailable. ${ }^{21}$ Instead, I will rely on specification choices in order to minimize the effects of simultaneity. First, a considerable amount of structure has been imposed in constructing the TFP indices (see Appendix B). Second, problems arising from the usage of common deflators should not be a major problem, because the R\&D figures are based on economy-wide deflators while the TFP indices use industry-specific price data. Third, the estimation equations include time fixed effects which control for shocks that affect the entire sample in a given year. I will also provide separate estimates for the sample of low-R\&D industries. Unlike transportation, chemicals, and machinery-the industries that account for most of the R\&D (see Table 1)-, the R\&D expenditures of the eight low-R\&D industries are too small to significantly affect the economy-wide innovative activity. Therefore, simultaneity problems-if present in the full sample-will be muchreduced in this case, and the extent to which these estimates are similar to those obtained with the full sample will shed light on whether simultaneity is likely to be a problem.

Lastly, country-by-industry fixed effects control for time-invariant factors that generate a spurious correlation between the regressors and the error term. These fixed effects capture differences in productivity levels which are due to factors other than R\&D conditional on geographic, trade, FDI, or language patterns. As an example, the composition of products within the two- to three-digit industries of the sample might vary by country, and this could be correlated with distance. Then an alternative to the geographically-limited-scope-of-technology-diffusion hypothesis is a technology matching explanation: if the degree to which one country's technology is suited to the needs of other countries is inversely related to geographic distance, productivity in Japan, e.g.,--which is on average further away from its G-7 partners than the other countries-could be relatively low just because Japan's G-7 partners generate technology that is relatively unproductive in Japan. Clearly, such differences in productivity would not exist because of a geographically limited scope of technology

\footnotetext{
${ }^{21}$ See also Griliches and Mairesse (1998) who give an overview of a number of approaches whose main common goal it is to identify production function parameters by avoiding simultaneity problems.
} 
diffusion. Analogous arguments can be made with respect to trade, FDI, and communication links.

Thus, the country-by-industry fixed effects are important to avoid obtaining inconsistent estimates and spurious results in the analysis that follows. ${ }^{22}$

\section{Estimation results}

\subsection{Geographic distance in international technology diffusion}

The first set of results addresses the question whether international technology diffusion is geographically localized or not (see Table 3). The dependent variable is the relative productivity level as defined in equation (1). The regressors are fixed effects for each year and for each country-by-industry combination, the domestic R\&D stock, and the R\&D stocks of the partner countries interacted with bilateral distance as described above. The estimation method is non-linear least squares. ${ }^{23}$

In the first result column, I estimate the exponential specification of (2) shown earlier. The productivity effect from $\mathrm{R} \& \mathrm{D}, \beta$, is estimated with $\beta=0.039 .{ }^{24}$ This number is in the range of values suggested by comparable studies. ${ }^{25}$ The parameter $\gamma$, which measures the relative potency of distance-adjusted foreign $\mathrm{R} \& \mathrm{D}$, is estimated to be $\gamma=1.111$, and the parameter $\delta$, which determines the extent to which foreign $R \& D$ is effective in determining productivity, is estimated at 0.147 . This

\footnotetext{
${ }^{22}$ Another concern is that the TFP variable might be stationary while the R\&D stocks could be trending over time. The theory of panel unit root and cointegration analysis that then would apply in the non-linear setting of this paper is not fully developed to date. In that case, I would therefore rely primarily (and imperfectly) on the time fixed effects $\alpha_{t}$ to address this issue. For an investigation of these time-series issues in the estimation of spillovers in linear regression models, see Edmond (2000).

${ }^{23}$ I have normalized the distance measure $D_{c g}$ so that $D_{c g}=1$ is equal to 341 kilometers, the shortest bilateral distance in the sample (between Paris and London). This affects the size of the parameters, but not the size of the other statistics discussed below.

${ }^{24}$ I rely mainly on bootstrapped standard errors for inference. They seem to be preferred, and in any case, they are often much larger than conventional asymptotic standard errors. The bootstrapped errors are heteroskedasticityconsistent (through block-wise resampling for each country-by-industry combination) and relatively robust to serial correlation (by resampling two consecutive errors at a time); see Andrews (1999) for references and further results. To be conservative, I report asymptotic standard errors when they are clearly larger, which is sometimes the case especially for the parameter $\gamma$. I have also examined whether spatial correlation remains in the residuals, without finding much evidence for it.

${ }^{25}$ For studies at this level of aggregation, Griliches (1995) reports typically estimates that are somewhat higher; however, many of the earlier studies do not consider productivity relative to the sample mean, as I do here.
} 
estimate suggests that effective $\mathrm{R} \& \mathrm{D}$ (the term $\gamma S_{g i t} e^{-\delta D_{c g}}$ ) is falling with distance. In specification (3.2), I allow for different R\&D sender effects for the U.S., Japan, and Germany (the G-3-, or, the three major R\&D countries, with parameter $\gamma_{2}$ ) on the one, and Canada, France, Italy, and the U.K. (with parameter $\gamma_{1}$ ) on the other hand. The G-3 technology sending effect appears to be somewhat larger than that of the non-G-3 countries, but to constrain all $\gamma$ 's to equal one, as in specification (3.3), is actually marginally preferred according to Akaike's Information Criterion. ${ }^{26}$

The distance parameter $\delta$ is estimated to be positive throughout. This finding is consistent with the idea that technological knowledge is localized, because it implies that the R\&D of countries that are far away from a given country contributes less to its productivity than the R\&D from near-by countries. In specification (3.4), I estimate the distance class specification (3) to see whether this result is robust. The parameter $\eta$ is estimated to be positive, which confirms that the productivity effects from foreign R\&D are localized for the G-7 countries. Recall that the distance class breakpoints are 2,000 and 7,500 kilometers. This means that $\eta$ is identified from the difference in R\&D effects of the European G-7 countries in Europe and the U.S.-Canada effect (less than 2, 000 kilometers), versus technology diffusion between North America and Europe (between 2,000 and 7,500 kilometers), versus technology diffusion to and from Japan. Together with the estimate of $\gamma$, the estimate of $\eta=1.01$ suggests that the value of a foreign G-7 dollar of $\mathrm{R} \& \mathrm{D}$ per domestic dollar is on average seventy-four percent (i.e., $\gamma(1+\eta)=0.74$ ) below 2,000 kilometers, it is roughly $37 \%$ (i.e., $\gamma=0.368$ ) across the Atlantic, while to and from Japan, the average value of a dollar of foreign R\&D is essentially zero (i.e., $\gamma(1-\eta) \approx 0)$.

For the exponential functional form in columns (3.1) to (3.3), an interesting statistic to compute is the half-life distance of $R \& D$, that is, the distance at which half of the $R \& D$ sent out from a technology-producing country has disappeared. This value $D^{*}$ is calculated from $\frac{1}{2} S=S e^{-\delta D^{*}}$,

\footnotetext{
${ }^{26}$ Akaike's Information Criterion (AIC) is defined as $\ln \left(\frac{e^{0} e}{n}\right)+2 k / n$, where $e^{\prime} e$ is the residual sum of squares, $n$ is the number of observations, and $k$ is the number of estimated parameters. The table also reports the $R^{2}$.
} 
leading with $\delta=0.147$ from (3.1) to $D^{*}=4.72$, or ca. 1,600 kilometers. Another measure of the strength of international technology diffusion in a given bilateral relation is the value of one foreign dollar of R\&D per one dollar of domestic $\mathrm{R} \& \mathrm{D}$, equal to $\gamma \exp \left(-\delta D_{c g}\right)$. This is shown for all bilateral relations in Figure 3. For instance, according to the estimates in (3.2), the average value of a dollar of U.S. R\&D in Canada is $78 \%$ of the value of a domestic dollar of Canadian R\&D, and a dollar of German R\&D in Italy has $64 \%$ of the domestic-R\&D effect. Clearly, the distance effects implied by these estimates are quite strong, suggesting in particular little technology diffusion to and from Japan. To compare the results of the exponential and the distance class specifications, I have computed the average relative foreign $R \& D$ value within North America and Europe, respectively, and the average relative foreign $\mathrm{R} \& \mathrm{D}$ value for bilateral relationships involving Japan. For the former, one obtains $67 \%$ in the exponential specification, compared to $74 \%$ in the distance class specification, while the average for relationships involving Japan is estimated to equal zero in both the exponential and distance class specifications. Thus, the two specifications give broadly similar results. I now turn to analyzing the robustness of these findings.

\subsection{Sensitivity analysis}

The results of this analysis are reported in Table 4. I use the exponential functional form for the results presented in columns one to three, while the distance class specification is employed for the remaining columns four and five. In the first specification only the eight low-R\&D industries are included. I estimate $\beta$ at 0.025 -significantly larger than zero at a $12 \%$ level-, down from 0.040 in the full sample, and the distance parameter $\delta$ is now also slightly lower. ${ }^{27}$ The second column presents estimates when TFP indices are based on gross output instead of value added, which is an alternative

\footnotetext{
${ }^{27}$ Because the industry $\mathrm{R} \& \mathrm{D}$ elasticity $\varepsilon_{i}$ is related to the return to $\mathrm{R} \& \mathrm{D}, \rho_{i}$ by $\varepsilon_{i}=\rho_{i} \frac{S_{\mathrm{i}}}{F_{i}}, \forall i$, if arbitrage equalizes the return to $\mathrm{R} \& \mathrm{D}$ across industries $\left(\rho_{i}=\rho, \forall i\right)$, then $\varepsilon_{i}$ varies with $S_{i}$. This could explain the drop of the coefficient $\beta$ (which is positively related to $\varepsilon_{i}$ ) when the sample contains the relatively low-R\&D industries only.
} 
approximation to true productivity. The distance parameter is estimated somewhat higher and the relative foreign $\mathrm{R} \& \mathrm{D}$ parameter is lower than before.

Using all-manufacturing PPP exchange rates instead of industry-specific exchange rates leads also to a stronger distance effect $(\delta=0.273$ in specification 4.3$)$. The distance effect estimated with TFP indices based on the assumption of increasing returns with a scale elasticity of 1.05 in (4.4) are similar to the distance effect in the benchmark result of (3.4). Finally, when factor input data is not adjusted for differences in input utilization, the $\mathrm{R} \& \mathrm{D}$ effect $\beta$ is considerably higher than in the corresponding specification with adjusted TFP data (compare (4.5) with (3.4)). This suggests that one picks up a substantial amount of spurious correlation when cyclical effects that affect both input utilization and $\mathrm{R} \& \mathrm{D}$ are not controlled for. Also here, though, one estimates a relatively large difference in the strength of technology diffusion across distance $(\eta=0.716)$.

In unreported analysis, I have used other combinations of data samples and specifications from Table 3, as well as a number of other specifications, such as lagged $R \& D$. There is evidence that some of the variation in productivity levels is explained only by the variables jointly. ${ }^{28}$ Overall though, I estimate a robust and significant geographic localization effect in international technology diffusion. In the exponential specification, the parameter $\beta$ is about 0.04 to 0.07 , varying in a reasonable way across different samples and data constructions. The relative foreign R\&D effects of the G-3 countries might be somewhat larger than for the other four countries, but this adds relatively little in terms of regression fit. In the distance class specification, the parameter $\beta$ is of similar magnitude, if somewhat less precisely estimated, and the estimates of $\eta$ lead to the same qualitative finding regarding the localization of international technology diffusion. Quantitatively, the magnitude of the distance effect varies across specifications. For the exponential functional form, the estimates of $\delta$ range from 0.123 to 0.300 , which corresponds to a half-life distance of about 800 to 1,900 kilometers.

\footnotetext{
${ }^{28}$ In the exponential specification, the bootstrap analysis reveals that the parameters $\beta$ and $\delta$ are positively correlated, for instance.
} 
In the distance class specification, $\eta$ varies from about 0.7 to 1.0 , which corresponds to a $70 \%$ to $100 \%$ premium (discount, respectively) for technology diffusion among countries that are below 2, 000 (above 7,500, respectively) kilometers apart, relative to technology diffusion between North America and Europe.

\subsection{Technology diffusion over time}

In this section I turn to changes in degree of international technology diffusion over time. The exponential specification is extended to

$$
\ln F_{c i t}=\alpha_{c i}+\alpha_{t}+\beta \ln \left[S_{c i t}+\sum_{g \neq c} \gamma\left(1+\gamma^{t i} I_{t}\right) S_{g i t} e^{-\delta\left(1+\delta^{t i} I_{t}\right) D_{c g}}\right]+\varepsilon_{c i t}, \forall c, i, t
$$

Here, $I_{t}$ is an indicator variable that is equal to one for the years 1983 to 1995 and zero otherwise, and there are two additional parameters, $\gamma^{t i}$ and $\delta^{t i}$. The former picks up any change in the overall effect from foreign $\mathrm{R} \& \mathrm{D}$, whereas the latter indicates whether the degree of localization of technology diffusion has changed. Values of $\delta^{t i}<0$ are consistent with technological knowledge becoming more global over time. See Table 5 for the results.

In specification (5.1), the parameter $\gamma^{t i}$ is constrained to zero. Relative to specification (3.1), the estimate of $\beta$ is now somewhat higher. More importantly, the distance estimate increases from 0.147 to 0.490 , while $\delta^{t i}$ is estimated to equal $\delta^{t i}=-1.188$. These estimates suggest a distance parameter of 0.490 for the subperiod $1970-82$, and of $0.490 \times(1+(-1.188))=-0.092$ for the subperiod of 1983-95. With a standard error for $\delta^{t i}$ of 0.222 , the distance effect in the second subperiod could be equal to zero, suggesting that geographic distance plays no role anymore by the end of the sample period. The next column in Table 5 indicates that the finding of less localization is independent of

the change in the value of foreign $\mathrm{R} \& \mathrm{D}: \gamma^{t i}$ is estimated to equal 0.072 , not significantly different from zero, and the estimate of $\delta^{t i}$ remains by and large unchanged. 
In the distance class specification, I estimate the parameter $\eta^{t i}$ in the expression $\eta \times\left(1+\eta^{t i} I_{t}\right)$, analogously to $\delta^{t i}$. The point estimate of $\eta^{t i}$ in specification (5.3) is equal to -0.778 , which suggests that the strength of technology diffusion during the 1990s varied substantially less across classes than it had during the early 1970s. In specification (5.4), the results for the exponential specification for the sample of the eight relatively low R\&D-intensive industries is shown. Relative to the value of $\delta=0.138$ for the entire sample period (see 4.1), also $\delta$ here is higher for the years 1970-82, and lower for the years 1983-95. In fact, one cannot reject the hypothesis that there is no distance effect during the later subperiod, which confirms the patterns obtained for the entire sample.

Overall, these results suggest that international technology diffusion has become much less localized over the sample period. In Figure 4, I show the total value of foreign G-7 country R\&D received by Japan, France, and Canada over time (based on 5.3). The figure highlights the fact that the total value of foreign $R \& D$ received by these countries has been converging sharply over time according to these estimates: while Japan received essentially zero in the early 1970s and France a total of about four dollars per dollar of domestic R\&D, by the 1990s the value of the technology received by France was only about $30 \%$ higher than the corresponding value that benefited Japan.

Can this finding explain the dynamics of the productivity distribution across G-7 countries that emerges from Figure 2? As noted earlier, ceteris paribus one expects productivity convergence as technology becomes more global in the world. The overall downward trend in the variation of average productivity between 1970-95 is broadly consistent with that. The period of productivity divergence between 1990-95 is probably not being picked up by these over-time estimates yet as the subperiod mid-points are the years 1976 and 1989. In general, however, one must use caution here, because the link between the less-localization finding and convergence of productivity in Figure 2 is not a tight one. The estimated decrease of localization is only an average effect after a substantial amount of unobserved heterogeneity is controlled for, and as long as technology diffusion is not complete, 
immediate, as well as universal, less localization need not go hand in hand with convergence of productivity.

The next section analyzes a number of specific technology diffusion mechanisms.

\subsection{Beyond Distance: Trade, Foreign Direct Investment, and Communication as Channels of International Technology Diffusion}

Table 6 shows the results of examining these three mechanisms of technology diffusion. I restrict myself to the exponential specification and the TFP variable defined in (1) to keep the number of regression results relatively low. The bilateral imports variable $M_{c g}$, as well as the FDI variable $V_{c g}$ and the language variable $B_{c g}$ are introduced analogously to distance. For instance,

$$
\ln F_{c i t}=\alpha_{c i}+\alpha_{t}+\beta \ln \left[S_{c i t}+\sum_{g \neq c} S_{g i t} e^{\tau M_{c g}}\right]+\varepsilon_{c i t}, \forall c, i, t
$$

is the imports specification, where $\tau$ is the parameter corresponding to the import share variable. A positive value of $\tau$ is consistent with bilateral imports raising the level of technology diffusion.

Specification (6.1) shows the basic geographic-distance result for comparison (see (3.3) in Table 3 ), while the second specification in Table 6 is equation (5). ${ }^{29}$ The estimate of $\beta$ changes relatively little, while the value of $\tau$ is positive, equal to $\tau=0.403 .{ }^{30}$ In specification (6.3), I use the FDI variable analogously and estimate the corresponding parameter at $\psi=0.377$. Also the language skills variable enters with a positive coefficient (specification 6.4). There is a major effect here on

\footnotetext{
${ }^{29}$ To facilitate the non-linear estimation, I have scaled the trade, FDI, and language shares as follows: $M_{c g}$ is multiplied by $10^{2}, V_{c g}$ by $10^{3}$ and $B_{c g}$ by 10 .

${ }^{30}$ An estimate of $\tau$ larger than zero means that the relative effect from foreign R\&D exceeds that from domestic $\mathrm{R} \& \mathrm{D}$ in all bilateral relationships as long as $\gamma$ is constrained to equal one. This is not very plausible, so that I have also experimented with estimating $\gamma$ and $\tau$ jointly. As expected, $\gamma$ then tends to be lower than one. However, freeing up the parameter $\gamma$ makes the specification less robust. Because the emphasis here is on estimating the parameter $\tau$ (as well as $\psi$ and $\lambda$ below, plus comparing them), I give a high priority to robustness and have therefore kept the parameter $\gamma$ constrained to one. If one sets a lower value for $\gamma$ or estimates the parameter, this does not lead to qualitatively different findings in the comparison of $\tau, \psi$, and $\lambda$; instead, it primarily affects the fixed effects estimates.
} 
the size of the $R \& D$ coefficient as well: $\beta$ is estimated at 0.103 , versus $\beta=0.055$ in the distance specification. These results suggest that each candidate channel might indeed have a positive effect on international technology diffusion. Notice that to the extent that the differences in empirical fit between the first four regressions in Table 6 are significant, that of the distance specification is lowest, followed by the FDI and the language skills specification, while the bilateral imports specification has the best fit.

It is important to consider more than one channel of diffusion at a time to learn about their relative strength, even though this makes the results less robust due to collinearity among the spillover channels. The following results are obtained: When distance is introduced together with the import shares in the exponential expression-as in $\exp \left(-\delta D_{c g}+\tau M_{c g}\right)$-, this reduces the estimate of $\tau$ by about two thirds, from 0.403 in (6.2) to $\tau=0.130$ in (6.5). Thus, differences in import patterns account no better for a substantial amount of variation in bilateral technology diffusion than do differences in distance. In equation (6.6), I have included the FDI variable together with distance. This results in a much larger estimate of $\beta$ and a higher value of $\delta$, while the FDI parameter $\psi$ stays about the same relative to the FDI-only specification (6.3).

Specification (6.7) introduces distance together with the language skills variable. The coefficient on the language variable remains positive, while the estimate of the distance parameter turns negative, albeit not significantly different from zero. ${ }^{31}$ Equation (6.8) introduces import and FDI patterns together with the language skills variable. All three variables enter with a positive coefficient. Finally, when I add the distance variable to this, the point estimate of $\delta$ is negative, while the other three point estimates remain positive. The fit of the regression is marginally improved through the inclusion of distance, but in contrast to the trade, FDI, and language parameters, $\delta$ is

\footnotetext{
${ }^{31}$ One explanation for this is that the language variable picks up a relatively strong effect from U.S. R\&D in Canada, plus an effect from U.S. R\&D in Europe that is stronger than one would think on the basis of distance. Also, the language variable appears to identify stronger technology inflows in Japan from English-language countries than from central European countries, all of which are roughly the same distance away from Japan.
} 
not significantly different from zero. ${ }^{32}$

I now turn to the absolute magnitude of inward technology diffusion, as well as the breakdown of the total effect by spillover channel (based on the estimates of specification 6.8 ). Let $\Gamma_{c}$ be the sum of the three effects for a given technology recipient country, $\Gamma_{c} \equiv \sum_{g}\left(\tau M_{c g}+\psi V_{c g}+\lambda B_{c g}\right), \forall c .{ }^{33}$ Also, denote by $s_{c}$ the share of the total effect by recipient country, $s_{c} \equiv \Gamma_{c} / \Gamma$, where $\Gamma \equiv \sum_{c} \Gamma_{c}$. First, the estimation results suggest that Canada benefits by far the most from foreign G-7 technology, with a share of $s_{C A N}=0.256$. This is primarily the result of Canada's links to the U.S., from which Canada imports a relatively high share, whose subsidiaries have a strong presence in Canada, and the fact that in both countries, the English language is used. Canada is followed by the U.K., and the U.S., with $s_{U K}=0.154$ and $s_{U S}=0.151$, respectively. France, Italy, and Germany are next $\left(s_{F R A}=0.137, s_{I T A}=0.128\right.$, and $\left.s_{G E R}=0.108\right)$, whereas Japan benefits least from foreign G-7 technology according to these estimates $\left(s_{J P}=0.066\right)$.

For the analysis of the relative strength of the diffusion mechanisms, let $s_{c}^{\tau}$ be the share of the total effect for country $c$ due to the contribution of imports, $s_{c}^{\tau} \equiv\left(\sum_{g} \tau M_{c g}\right) / \Gamma_{c}$, and let $s_{c}^{\psi}$ and $s_{c}^{\lambda}$ be the shares due to FDI and language skills, defined analogously. Also, let $s^{\tau}, s^{\psi}$, and $s^{\lambda}$ be the average shares for a given channel of technology diffusion across countries (for instance, $s^{\tau} \equiv\left(\sum_{c} s_{c}^{\tau}\right) / C$. I estimate that the effect due to imports is highest on average, with $s^{\tau}=0.691$, while the FDI and language effects are equal to $s^{\psi}=0.148$ and $s^{\lambda}=0.161$, respectively. This points to a relatively strong effect due to embodied technology diffusion in form of imports. At the same time, the other two channels are far from being negligible. Figure 5 shows, for instance, that the absolute effect from

\footnotetext{
${ }^{32}$ There might be important interactions between these channels of technology diffusion, for instance, the effect from language skills could be higher, the greater is the bilateral geographic distance. In principle, one could test for this by including an interaction variable, $D_{c g} \times B_{c g}$, and estimate an additional coefficient in the exponential term. In practice though, a comprehensive analysis of interaction terms appears to stretch the possibilities of the data to some extent, so I do not include it here. Note, however, that the non-linear specification picks up some interaction effects already as it is.

${ }^{33}$ This analysis of inward technology diffusion focuses on the term in the exponential part of $\sum_{g} S_{g} e^{\tau M_{\mathrm{cg}}+\psi V_{\mathrm{cg}}+\lambda B_{\mathrm{cg}}}$. I do this for ease of interpretation, but it should be kept in mind that differences in effective R\&D from abroad are also due to differences in $S_{g}$ as well as the interaction of $S_{g}$ with the exponential term.
} 
inward FDI in Canada exceeds that from imports in Japan. Moreover, the larger inward share of foreign-owned subsidiaries in Canada versus the U.K. explains $41.9 \%$ of the difference in total inward technology diffusion between these two countries. Another indication of the importance of FDI for inward technology diffusion comes from comparing the European countries: here, the U.K. attracts the largest share of FDI, and $36.2 \%$ of the U.K. advantage over Germany in terms of total inward technology diffusion is due to the U.K.'s higher level effect through FDI.

Language skills have the highest contribution to inward technology diffusion in the U.K. and the lowest in Japan: 43.4\% of the higher level of inward technology diffusion in the U.K. versus Japan can be attributed to the higher share of the population in the U.K. that speaks the languages of the G-7 technology source countries. Among the European countries, $76.8 \%$ of the higher level of technology inflows in the U.K. relative to Italy are due to differences in language skills. And if language skills in Germany would be the same as the (generally lower) language skills in Italy, Germany would benefit about $6 \%$ less from G-7 technology diffusion than it actually does.

Figure 6, which is also based on the results in (6.8), allows to compare the strength of bilateral technology diffusion across different country pairs by showing the share of a sender country in a given technology recipient's country total technology inflows (the sum of trade, FDI, and language channels; this is denoted as the TFL-based measure). For instance, $69.1 \%$ of technology diffusion to Canada originates from U.S. R\&D, while the share of the U.K. in Canada is much lower, equal to $13.5 \%$. The estimates also suggest that the U.S. is the major source of all technology inflows to Japan, with $63.0 \%$. Germany accounts for more than a third of the technology inflows into Italy and France, according to these estimates, but less than $20 \%$ of the inflows to the United Kingdom. Figure 7 indicates how these estimates differ from estimates simply based upon bilateral distance. ${ }^{34}$ On the

\footnotetext{
${ }^{34}$ I have computed the distance-based shares underlying Figure 7 from the inverse of the bilateral distances reported in Table 2.1-giving a measure of closeness-, before forming the share of a bilateral relation in the closeness total for a given country.
} 
horizontal axis are listed forty-two bilateral relations, with the technology recipient mentioned first, followed by the technology sender. For instance, the left-most bilateral relation gives the importance of French R\&D in the United Kingdom. It says that on the basis of these estimates, the distancebased shares overestimate the importance of France as a source of technology for the U.K. by circa thirty-four percentage points relative to the TFL-based measure, or put differently, France appears to be much less important for the U.K. than one would assume based on the close relative location.

It is not the case, however, that the importance of near-by countries is always estimated higher with the distance-based measure. In particular, as a source of technology for Canada, the U.S. is even more important according to the TFL-based measure than one would assume based on its relatively close location to Canada (CAN/US is 11th from the right). The TFL-based measure also gives a more plausible picture of the importance of Canada as a source of U.S. technology inflows than the distance-based measure: the relation US/CAN is second from the left, and the associated value suggests that the relative importance of Canada on the basis of distance is about twentyeight percentage points higher than according to the TFL-based measure. On the other end of the spectrum, the four right-most bilateral pairs all include the U.S. as a technology sender. This result confirms the notion that the U.S.'s importance for technology diffusion to G-7 countries other than Canada would be underestimated if a simple distance-based criterion is used to predict bilateral technology diffusion.

\section{Summary and discussion}

This analysis of technology diffusion among the seven major industrialized countries has produced a number of interesting results. First, geographic distance appears to have a strongly limiting effect on technology diffusion among these technology frontier-countries. While the estimates vary somewhat depending on specification, typically they imply a technology half-life in terms of distance of 800 
to 1,900 kilometers. Second, the degree of localization of technology diffusion has substantially declined over the sample period. Again, estimates vary somewhat, but it appears that the extent of localization has fallen by at least two thirds from the 1970s to the 1990s. Third, I have presented a number of findings on the importance of trade, FDI, and language skills for international technology diffusion, to which I turn below.

The effect that distance has on the scope of international technology diffusion according to some of my estimates is probably too high. One reason for this could be the fact that my analysis abstracts from the value of technological knowledge being heterogeneous. It is well-known from analyses of the value of patents that their distribution is very skewed. Because the technology that diffuses first is likely more valuable than the technology that diffuses later, my analysis underestimates the value of small stocks of diffused technology relative to larger stocks. In particular, taking account of heterogeneity might therefore raise technology diffusion to and from Japan. Caution is also needed to interpret the results on changes in technology diffusion over time. While there are several mechanisms which seem to be plausible a priori, the dramatic magnitude that I estimate, often eliminating the localization effect completely over only twenty-five years, suggests that it might be overstated.

As data on a larger set of countries, especially outside Europe, becomes available, it will be possible to re-examine the questions I have addressed. Moreover, it might be possible in the future to compute productivity indices that consistently account for differences in human capital across countries and industries. In terms of specification, I have focused on international within-industry effects, while technology diffusion between industries-that is, across technology space-is likely to be important as well. Further, the temporal dimension of technology diffusion has been collapsed into one point in time in my analysis that focuses on contemporaneous effects.

For the time being, then, what explains the level and the change in the localization effect that are estimated? I have considered the channels of trade, FDI, and direct communication, proxied by 
data on language skills, as alternatives to distance above. Recall that the interpretation of these findings requires caution for the reasons discussed in section 1.3. From this analysis, it appears that a substantial portion of the distance effect in technology diffusion, and may be all of it, can be accounted for by differences in trade, FDI, and communication links across countries. To the extent that this finding is confirmed by future research, this provides important information for areas where economic policy might be effective in fostering international technology diffusion. Out of the three channels, I estimate that trade is most important, with about two-thirds of the total diffusion effect, while differences in FDI and language skills account for about one-sixth each. ${ }^{35}$ These findings are to some extent specific to this sample of major OECD countries, and it will be interesting to see by how much the estimates change once the analysis is extended to a broader set of countries.

While it is possible to account for a substantial part of the distance effect in terms of trade, FDI, and communication links, much less can be said at this point on what has caused the decline in the degree of localization of technology over the sample period. Have transport costs for goods declined dramatically over the period of 1970-95? Direct evidence on this is scarce. Research in international trade using so-called gravity equations has frequently shown that the volume of trade falls sharply with geographic distance, but whether this effect has become substantially weaker during the sample period is not settled yet. ${ }^{36}$ Thus, it cannot be ruled out that less localization of technology diffusion is related to the higher level of economic integration through trade that has been observed in recent years. As for foreign direct investment, the rate of growth in multinational activity over the last two decades has been even higher than the rate of growth of world trade, which means that FDI might also be in part what is behind the decrease in localization of technology. And of course the recent

\footnotetext{
${ }^{35}$ Given the strong negative correlation of trade with distance, trade is more likely to pick up any remaining spurious regional effect that the econometric specification does not control for than the other two mechanisms. This suggests that the share of two-thirds is likely to be an upper bound for the relative importance of trade in technology diffusion.

${ }^{36}$ The estimate of the elasticity of trade with respect to distance is often not substantially smaller for more recent periods, but this appears to be due primarily to changes in the composition of goods trade that go unnoticed at the relatively high levels of aggregation that are frequently analyzed.
} 
development of new communication technologies and the internet are strong prima facie reasons of why technology might have become less localized. A definitive answer in this regard, however, must await the greater availability of relevant data, because to date, relatively little is available on the extent to which FDI activity, communication flows, and other indicators of channels of technology diffusion have changed over time. This will allow to go further than this paper can towards addressing the important question of what are the main causes, and implications, of the recent decline in the localization of technological knowledge. 
Table 1: Summary Statistics

Country

Symbol

Relative size in terms of GDP in sample*

(\%)

$\begin{array}{lc}\text { Canada } & \text { CAN } \\ \text { France } & \text { FRA } \\ \text { Germany } & \text { GER } \\ \text { Italy } & \text { ITA } \\ \text { Japan } & \text { JP } \\ \text { United Kingdom } & \text { UK } \\ \text { United States } & \text { US }\end{array}$

Industry

ISIC

\section{Relative size in terms of} output in sample

(\%)

$\begin{array}{lc}\text { Food } & 31 \\ \text { Textiles } & 32 \\ \text { Wood } & 33 \\ \text { Paper } & 34 \\ \text { Chemicals } & 351 / 2 \\ \text { Rubber } & 355 / 6 \\ \text { Non-met. Miner. } & 36 \\ \text { Basic Metals } & 37 \\ \text { Metal Products } & 381 \\ \text { Machinery, Instr. } & 382 / 5 \\ \text { El. Machinery } & 383 \\ \text { Transportation } & 384\end{array}$

3.15

12.89

15.15

11.67

14.36

9.16

33.62

100.00

14.66

8.62

4.73

9.79

8.21

3.39

4.75

7.13

8.19

12.79

7.00

10.73

100.00
Relative size in terms of $R \& D$ in sample**

(\%)

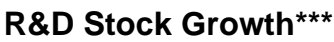

$$
\begin{array}{r}
1.44 \\
7.03 \\
11.78 \\
3.31 \\
23.53 \\
5.71 \\
47.19 \\
\\
100.00
\end{array}
$$

Relative size in terms of $R \& D$ in sample sa $^{\star \star \star \star}$

(\%)

$$
\begin{array}{r}
1.90 \\
0.56 \\
0.36 \\
1.03 \\
19.75 \\
1.70 \\
1.04 \\
2.63 \\
1.52 \\
17.22 \\
24.63 \\
27.67
\end{array}
$$

100.00
R\&D Stock Growth*

All countries

(\%)

9.17

7.59

13.77

7.29

9.00

7.69

8.02

7.83

10.41

9.78

9.33

8.41

*Shares computed from value of total manufacturing production in 1980

**Shares computed from total manufacturing R\&D in 1990

${ }^{* * *}$ Average annual growth of $R \& D$ stocks; $R \& D$ depreciation rate $=0.1$

**** Shares computed from value added in 1980; simple average across countries

${ }^{\star \star \star \star \star}$ Computed from R\&D expenditures in 1990; simple average across countries 
Table 2.1 Bilateral distance between capital cities (kilometers)

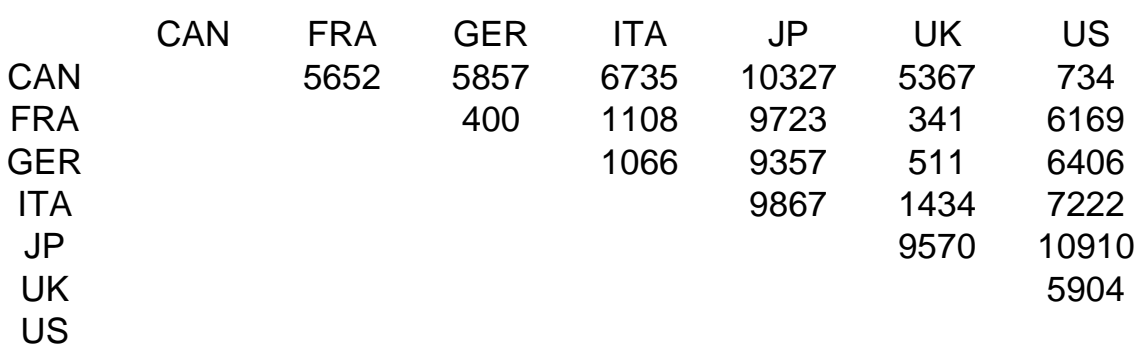

Table 2.2 Bilateral trade shares*

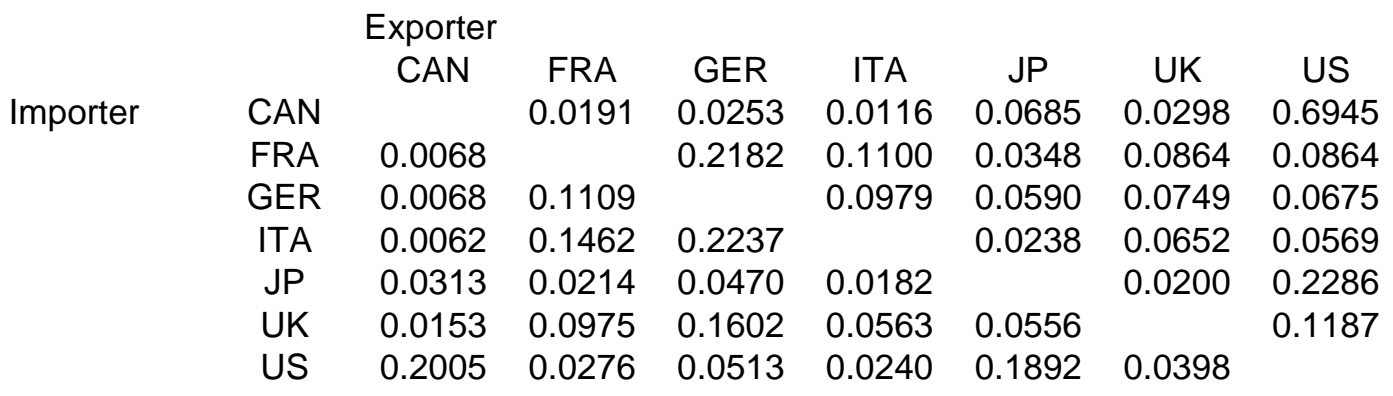

Table 2.3 Bilateral foreign direct investment shares ${ }^{\star *}$

\begin{tabular}{|c|c|c|c|c|c|c|c|c|}
\hline & & Outward & DI cour & & & & & \\
\hline & & CAN & FRA & GER & ITA & JP & UK & US \\
\hline FDI host & CAN & & 0.0186 & 0.0249 & 0.0049 & 0.0193 & 0.0594 & 0.1627 \\
\hline country & FRA & 0.0000 & & 0.0240 & 0.0000 & 0.0020 & 0.0163 & 0.0472 \\
\hline & GER & 0.0009 & 0.0045 & & 0.0017 & 0.0021 & 0.0031 & 0.0309 \\
\hline & ITA & 0.0012 & 0.0220 & 0.0120 & & 0.0023 & 0.0073 & 0.0290 \\
\hline & $J P$ & 0.0000 & 0.0001 & 0.0007 & 0.0000 & & 0.0005 & 0.0068 \\
\hline & UK & 0.0105 & 0.0109 & 0.0072 & 0.0000 & 0.0110 & & 0.0726 \\
\hline & US & 0.0163 & 0.0109 & 0.0135 & 0.0013 & 0.0169 & 0.0294 & \\
\hline
\end{tabular}

Table 2.4 Patterns of bilateral language knowledge ${ }^{\star \star \star}$

\begin{tabular}{|c|c|c|c|c|c|c|c|c|}
\hline & & Technol & yy send & & & & & \\
\hline & & CAN & FRA & GER & ITA & $J P$ & UK & US \\
\hline Technology & CAN & & 0.3100 & 0.0200 & 0.0200 & 0.0020 & 0.8400 & 0.8400 \\
\hline Recipient & FRA & 0.3200 & & 0.0900 & 0.0600 & 0.0007 & 0.3200 & 0.3200 \\
\hline & GER & 0.4100 & 0.1100 & & 0.0200 & 0.0006 & 0.4100 & 0.4100 \\
\hline & ITA & 0.2700 & 0.1900 & 0.0300 & & 0.0003 & 0.2700 & 0.2700 \\
\hline & $\mathrm{JP}$ & 0.0011 & 0.0001 & 0.0001 & 0.0000 & & 0.0011 & 0.0011 \\
\hline & UK & 1.0000 & 0.1400 & 0.0500 & 0.0100 & 0.0020 & & 1.0000 \\
\hline & US & 1.0000 & 0.0111 & 0.0210 & 0.0103 & 0.0022 & 1.0000 & \\
\hline
\end{tabular}

\footnotetext{
*Share of total manufacturing imports; Year 1991; source: Feenstra et al. (1997).

** Share of foreign-owned subsidiary employment in total employment; Year 1991; source OECD (1999c) and own estimates

${ }^{* * *}$ Share of population in recipient country that speaks the official language of the sender country

Year 1996/98; source: EU (1999), StatCan (2000), estimates based on JG (2000), and own estimates
} 


\begin{tabular}{|c|c|c|c|c|}
\hline & $\begin{array}{c}\text { Exponential } \\
\text { distance } \\
\text { eq. (2) } \\
(3.1)\end{array}$ & $\begin{array}{c}\text { Exponential } \\
\text { distance } \\
\mathrm{w} / \gamma_{1}, \gamma_{2} \\
(3.2)\end{array}$ & $\begin{array}{l}\text { Exponential } \\
\text { distance } \\
\quad \bar{\gamma}=1 \\
(3.3)\end{array}$ & $\begin{array}{l}\text { Distance } \\
\text { classes } \\
\text { eq. (3) } \\
(3.4)\end{array}$ \\
\hline$\beta$ & $\begin{array}{c}0.039 \\
(0.010)\end{array}$ & $\begin{array}{c}0.046 \\
(0.010)\end{array}$ & $\begin{array}{c}0.055 \\
(0.014)\end{array}$ & $\begin{array}{l}0.048^{\S} \\
(0.016)\end{array}$ \\
\hline$\gamma$ & $\begin{array}{c}1.111 \\
(0.186)\end{array}$ & & & $\begin{array}{c}0.368 \\
(0.095)\end{array}$ \\
\hline$\gamma_{1}$ & & $\begin{array}{c}0.992 \\
(0.068)\end{array}$ & & \\
\hline$\gamma_{2}$ & & $\begin{array}{c}1.197 \\
(0.067)\end{array}$ & & \\
\hline$\delta$ & $\begin{array}{c}0.147 \\
(0.045)\end{array}$ & $\begin{array}{c}0.199 \\
(0.028)\end{array}$ & $\begin{array}{l}0.123^{\S} \\
(0.030)\end{array}$ & \\
\hline$\eta$ & & & & $\begin{array}{c}1.010 \\
(0.139)\end{array}$ \\
\hline$n$ & 2184 & 2184 & 2184 & 2184 \\
\hline$R^{2}(\%)$ & 85.07 & 85.08 & 85.06 & 85.03 \\
\hline$A I C$ & -4.645 & -4.648 & -4.649 & -4.644 \\
\hline
\end{tabular}

*Dependent variable: multilateral TFP index, as defined in the text. Standard errors are in parentheses; $\beta$ measures the effect of domestic R\&D, $\gamma$ the relative effect from foreign $\mathrm{R} \& \mathrm{D}\left(\gamma_{1}\right.$ for CAN, FRA, ITA, and for the UK, and $\gamma_{2}$ for US, JP, and GER), and $\delta$ as well as $\eta$ determine the distance effect $(\delta>0$ and $\eta>0$ are consistent with distance-limited technology diffusion); $\mathrm{n}=$ number of observations, AIC = Akaike's Information Criterion, as defined in the text; ${ }^{\S}$ coefficient is only significantly different from zero at a $5 \%$ level. 
Table 4: Sensitivity analysis*

\begin{tabular}{|c|c|c|c|c|c|}
\hline & $\begin{array}{c}\text { Low R\&D } \\
\text { industries } \\
\text { (4.1) }\end{array}$ & $\begin{array}{l}\text { Output- } \\
\text { based TFP } \\
(4.2)\end{array}$ & $\begin{array}{l}\text { All-manufact. } \\
\text { PPP exch. rates } \\
\text { (4.3) }\end{array}$ & $\begin{array}{l}\text { TFP based } \\
\text { on IRS } \\
(4.4)\end{array}$ & $\begin{array}{c}\text { Unadjusted } \\
\text { TFP } \\
(4.5)\end{array}$ \\
\hline \multirow[t]{2}{*}{$\beta$} & $0.025^{\otimes}$ & 0.045 & 0.045 & $0.044^{\S}$ & $0.067^{\S}$ \\
\hline & $(0.016)$ & $(0.011)$ & $(0.011)$ & $(0.017)$ & $(0.018)$ \\
\hline \multirow[t]{2}{*}{$\gamma$} & & 0.737 & & 0.618 & 0.437 \\
\hline & & $(0.067)$ & & $(0.155)$ & $(0.066)$ \\
\hline$\delta$ & 0.138 & 0.300 & 0.273 & & \\
\hline \multirow{3}{*}{$\eta$} & $(0.079)$ & $(0.100)$ & $(0.021)$ & & \\
\hline & & & & 1.077 & 0.716 \\
\hline & & & & $(0.086)$ & $(0.067)$ \\
\hline$n$ & 1456 & 2184 & 2184 & 2184 & 2184 \\
\hline$R^{2}(\%)$ & 85.37 & 83.43 & 83.09 & 85.48 & 80.97 \\
\hline$A I C$ & -4.676 & -4.565 & -4.668 & -4.608 & -4.431 \\
\hline
\end{tabular}

*Dependent variable: multilateral TFP index, as defined in the text. Standard errors are in parentheses; $\beta$ measures the effect of domestic $R \& D, \gamma$ the relative effect from foreign $R \& D$, and $\delta$ as well as $\eta$ determine the distance effects $(\delta>0$ and $\eta>0$ means greater geographic distance is associated with less diffusion); $\mathrm{n}=$ number of observations, AIC $=$ Akaike's Information Criterion, as defined in the text; ${ }^{\otimes}$ coefficient is significantly larger than zero at a $12 \%$ level; ${ }^{\S}$ coefficient is significantly different from zero only at a $5 \%$ level. 


\begin{tabular}{|c|c|c|c|c|}
\hline & $\begin{array}{c}\text { Exponential } \\
\mathrm{w} / \Delta \text { in } \\
\text { distance effect } \\
\text { (5.1) }\end{array}$ & $\begin{array}{c}\text { Exponential } \\
\mathrm{w} / \Delta \text { in distance } \\
\text { and foreign effects } \\
\text { (5.2) }\end{array}$ & $\begin{array}{c}\text { Distance class } \\
\text { w/ } \Delta \text { in } \\
\text { distance effect } \\
\text { (5.3) }\end{array}$ & $\begin{array}{c}\text { Exponential w/ } \Delta \text { in } \\
\text { distance effect } \\
\text { Low R\&D Industries } \\
\text { (5.4) }\end{array}$ \\
\hline$\beta$ & $\begin{array}{c}0.052 \\
(0.010)\end{array}$ & $\begin{array}{c}0.057 \\
(0.010)\end{array}$ & $\begin{array}{c}0.067 \\
(0.012)\end{array}$ & $\begin{array}{c}0.066 \\
(0.013)\end{array}$ \\
\hline$\gamma$ & $\begin{array}{c}1.127 \\
(0.044)\end{array}$ & $\begin{array}{c}1.104 \\
(0.123)\end{array}$ & $\begin{array}{c}0.498 \\
(0.040)\end{array}$ & \\
\hline$\delta$ & $\begin{array}{c}0.490 \\
(0.091)\end{array}$ & $\begin{array}{c}0.466 \\
(0.073)\end{array}$ & & $\begin{array}{c}0.472 \\
(0.069)\end{array}$ \\
\hline$\eta$ & & & $\begin{array}{c}1.012 \\
(0.124)\end{array}$ & \\
\hline$\gamma^{\mathrm{ti}}$ & & $\begin{array}{l}0.072^{\natural} \\
(0.071)\end{array}$ & & \\
\hline$\delta^{\mathrm{ti}}$ & $\begin{array}{r}-1.188 \\
(0.222)\end{array}$ & $\begin{array}{l}-1.193 \\
(0.305)\end{array}$ & & $\begin{array}{l}-1.174 \\
(0.304)\end{array}$ \\
\hline$\eta^{\mathrm{ti}}$ & & & $\begin{array}{l}-0.778 \\
(0.079)\end{array}$ & \\
\hline $\mathrm{n}$ & 2184 & 2184 & 2184 & 1456 \\
\hline$R^{2}(\%)$ & 86.65 & 86.70 & 85.35 & 86.75 \\
\hline$A I C$ & -4.752 & -4.755 & -4.666 & -4.773 \\
\hline
\end{tabular}

*Dependent variable: multilateral TFP index as defined in the text. Standard errors are in parentheses; $\beta$ measures the effect of domestic $\mathrm{R} \& \mathrm{D}, \gamma$ the relative effect from foreign $\mathrm{R} \& \mathrm{D}$, and $\delta$ as well as $\eta$ determine the distance effects $\left(\delta>0\right.$ and $\eta>0$ says that greater distance is associated with a lower productivity effect). The parameters $\gamma^{\mathrm{ti}}, \delta^{\mathrm{ti}}$, and $\eta^{\mathrm{ti}}$ estimate changes in the overall foreign $\left(\gamma^{\mathrm{ti}}\right)$ and distance effects; $\mathrm{n}=$ number of observations, AIC $=$ Akaike's Information Criterion, as defined in the text; ${ }^{\circledR}$ not significantly different from zero at standard levels. 


\begin{tabular}{|c|c|c|c|c|c|c|c|c|c|}
\hline & (6.1) & (6.2) & (6.3) & (6.4) & (6.5) & (6.6) & (6.7) & (6.8) & (6.9) \\
\hline \multirow[t]{2}{*}{$\beta$} & 0.055 & 0.057 & 0.053 & 0.103 & 0.081 & 0.125 & 0.087 & 0.082 & 0.068 \\
\hline & $(0.014)$ & $(0.011)$ & $(0.018)$ & $(0.018)$ & $(0.010)$ & $(0.012)$ & $(0.014)$ & $(0.011)$ & $(0.028)$ \\
\hline \multirow[t]{2}{*}{$\delta$} & 0.123 & & & & 0.191 & 0.232 & $-0.180^{\phi}$ & & $-0.124^{\Phi}$ \\
\hline & $(0.030)$ & & & & $(0.111)$ & $(0.082)$ & $(0.073)$ & & $(0.159)$ \\
\hline \multirow[t]{2}{*}{$\tau$} & & 0.403 & & & 0.130 & & & 0.578 & 0.765 \\
\hline & & $(0.031)$ & & & $(0.006)$ & & & $(0.064)$ & $(0.230)$ \\
\hline \multirow[t]{3}{*}{$\psi$} & & & 0.377 & & & 0.370 & & 0.081 & 0.073 \\
\hline & & & $(0.027)$ & & & $(0.046)$ & & $(0.017)$ & $(0.014)$ \\
\hline & & & & 0.390 & & & 0.662 & $0.574^{\oplus}$ & $0.975^{\oplus}$ \\
\hline$\lambda$ & & & & $(0.029)$ & & & $(0.100)$ & $(0.183)$ & $(0.555)$ \\
\hline$A I C$ & -4.649 & -4.668 & -4.661 & -4.664 & -4.678 & -4.689 & -4.685 & -4.694 & -4.697 \\
\hline
\end{tabular}

*Dependent variable: multilateral TFP index, as defined in the text. Standard errors are in parentheses; $\beta$ measures the effect of domestic $\mathrm{R} \& \mathrm{D}, \delta$ the distance effect $(\delta>0$ is consistent with localized spillovers), $\tau$ is the parameter on the import shares, $\psi$ is the parameter on the FDI shares, and $\lambda$ is the language parameter. If trade, FDI, or language facilitate technology diffusion, then $\tau, \psi$, or $\lambda$, respectively, are expected to be greater than zero; 2184 observations, AIC $=$ Akaike's Information Criterion, as defined in the text; ${ }^{\oplus}$ coefficient is only significant at the $10 \%$ level, ${ }^{\circledR}$ coefficient is not significantly different from zero at standard levels. 
Figure 1

Comparing relative productivity with and without correcting for differences in input usage

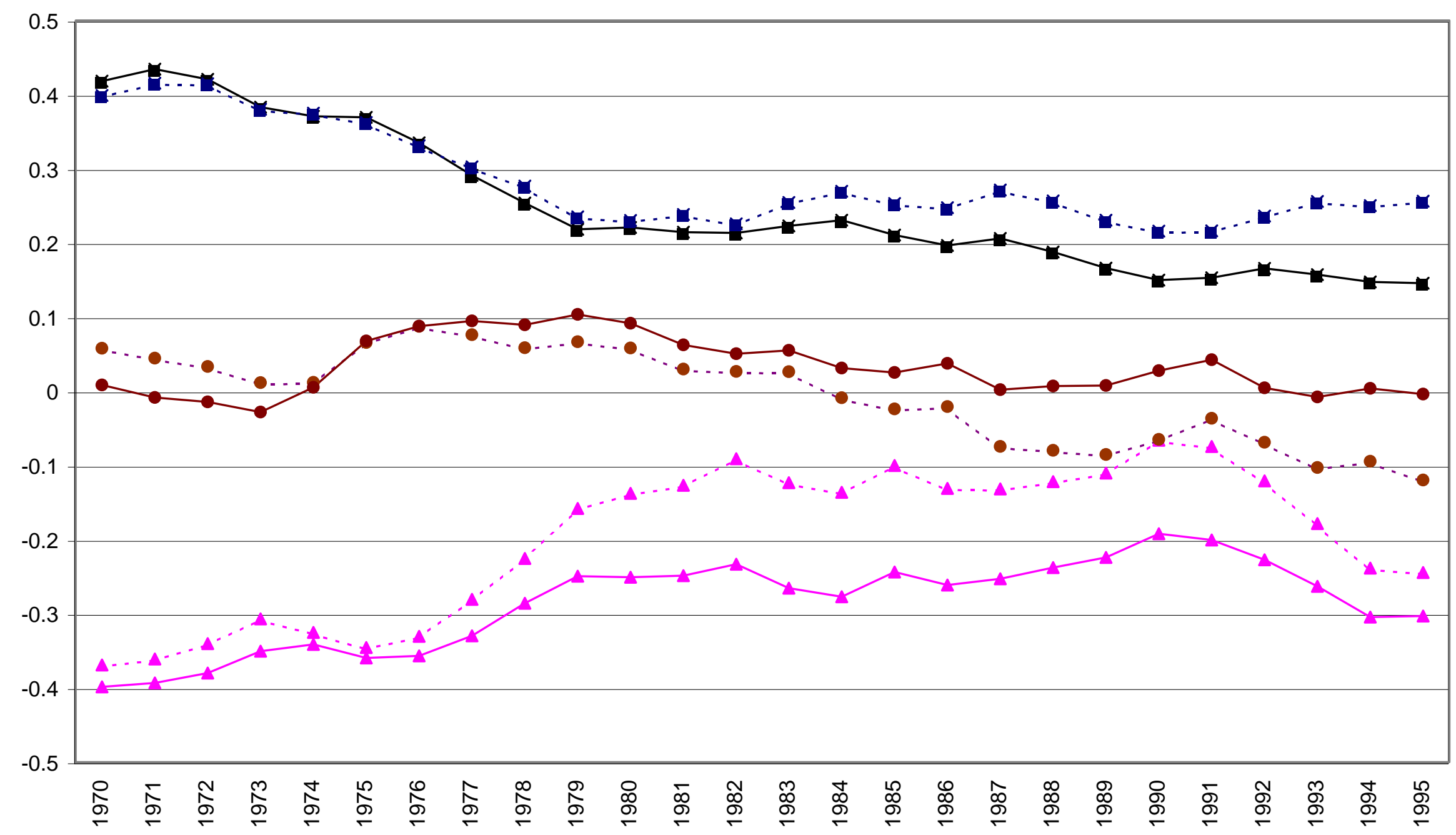


Figure 2

Productivity convergence or divergence: analysis within and between countries

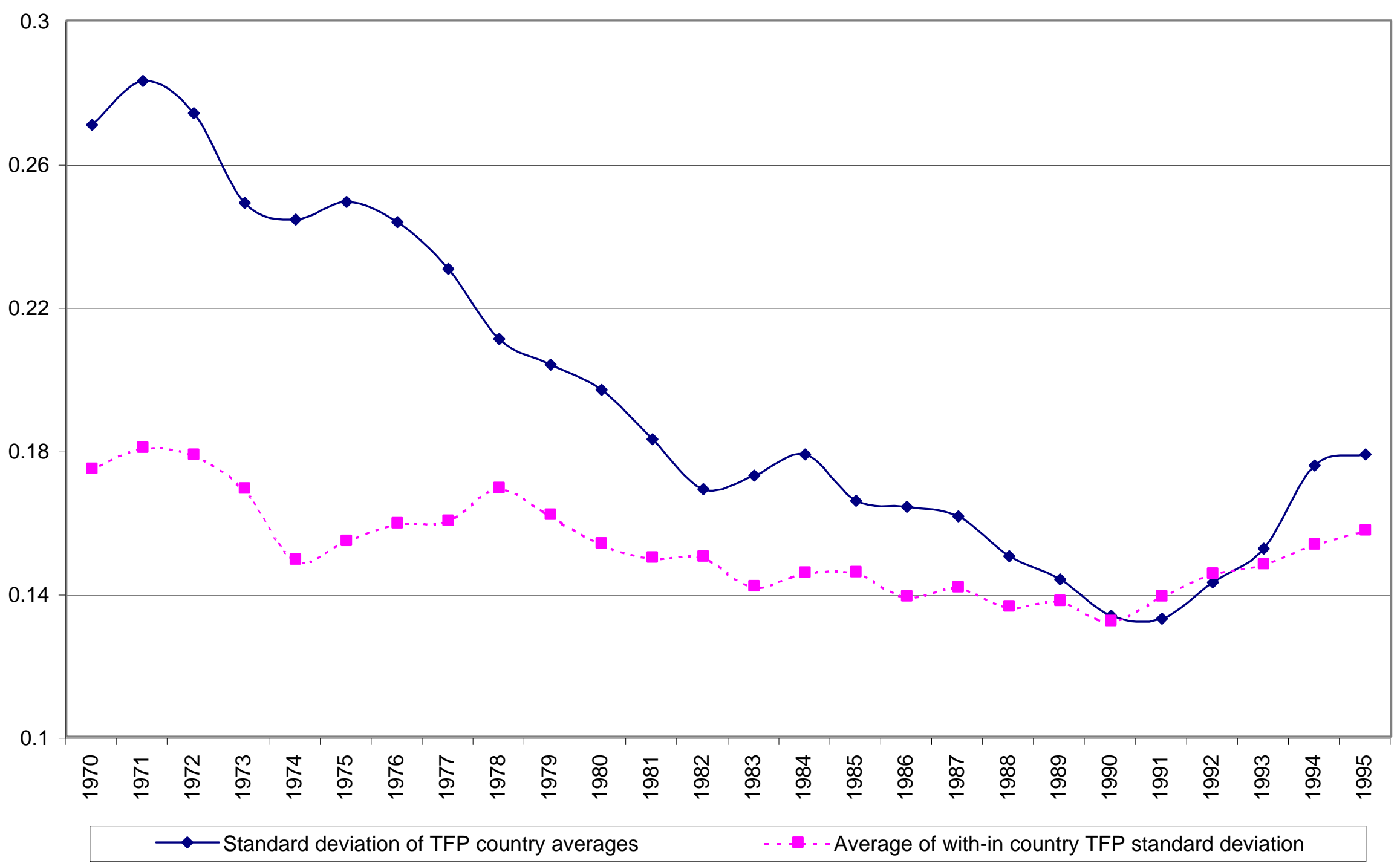


Figure 3

Bilateral technology diffusion conditional on geographic distance

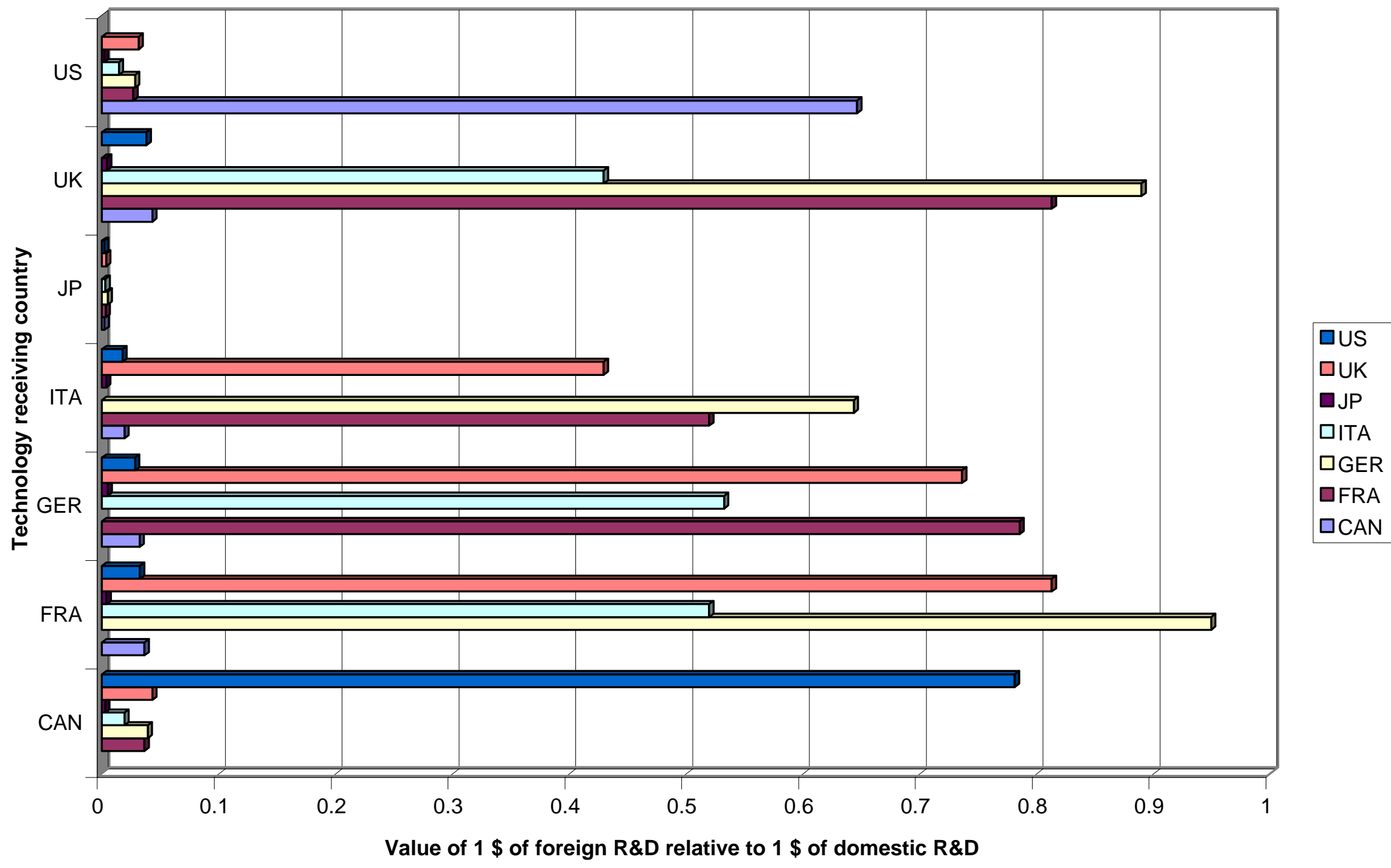


Figure 4

Changes in the geographic scope of international technology diffusion over time

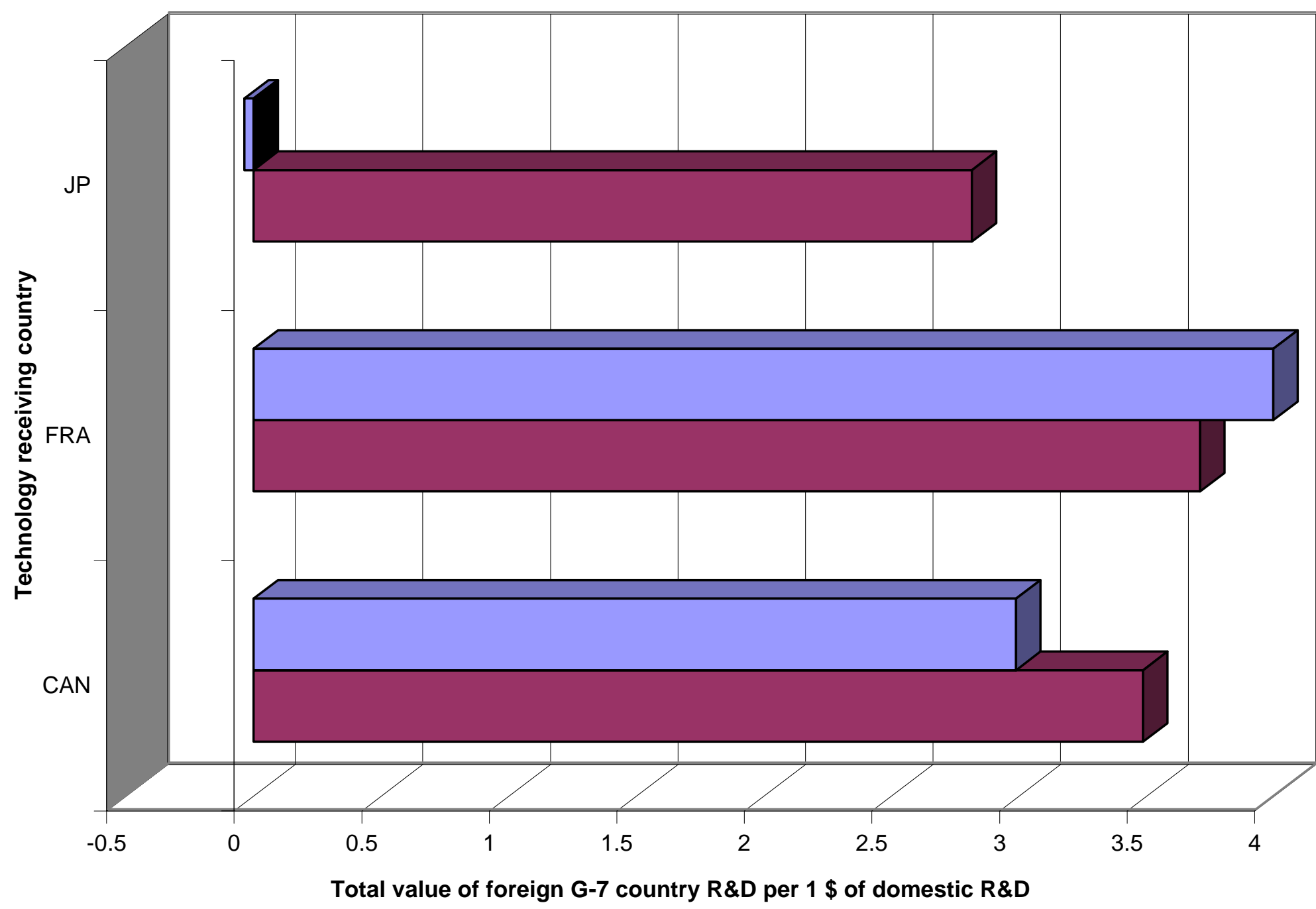


Figure 5

Total inward technology diffusion and relative importance of different channels

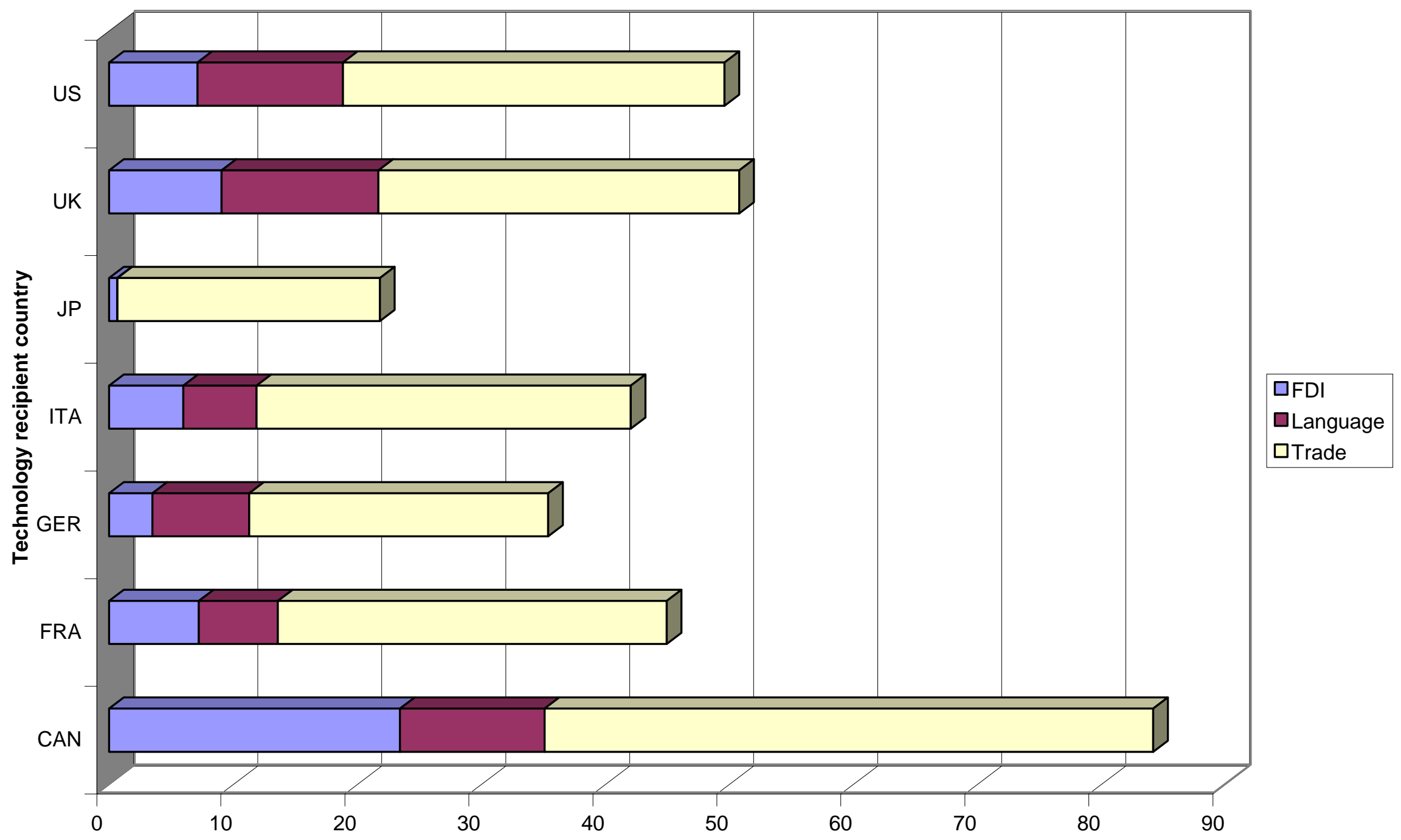


Figure 6

Relative Importance of G-7 Partner Countries in International Technology Diffusion All Channels

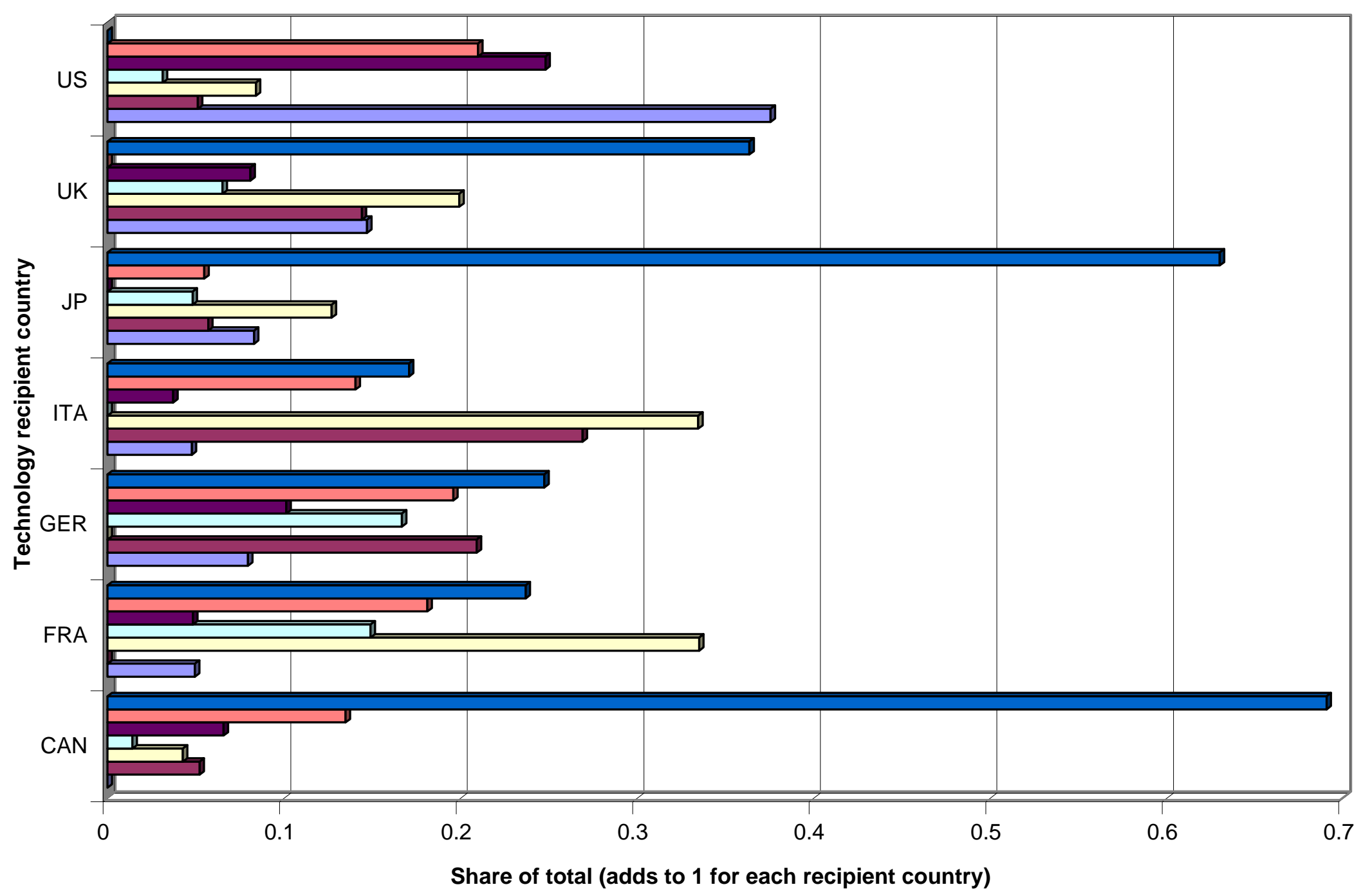


Figure 7

Comparison of a distance-based measure of the relative importance of foreign sources of technology with another based on trade, FDI, and language

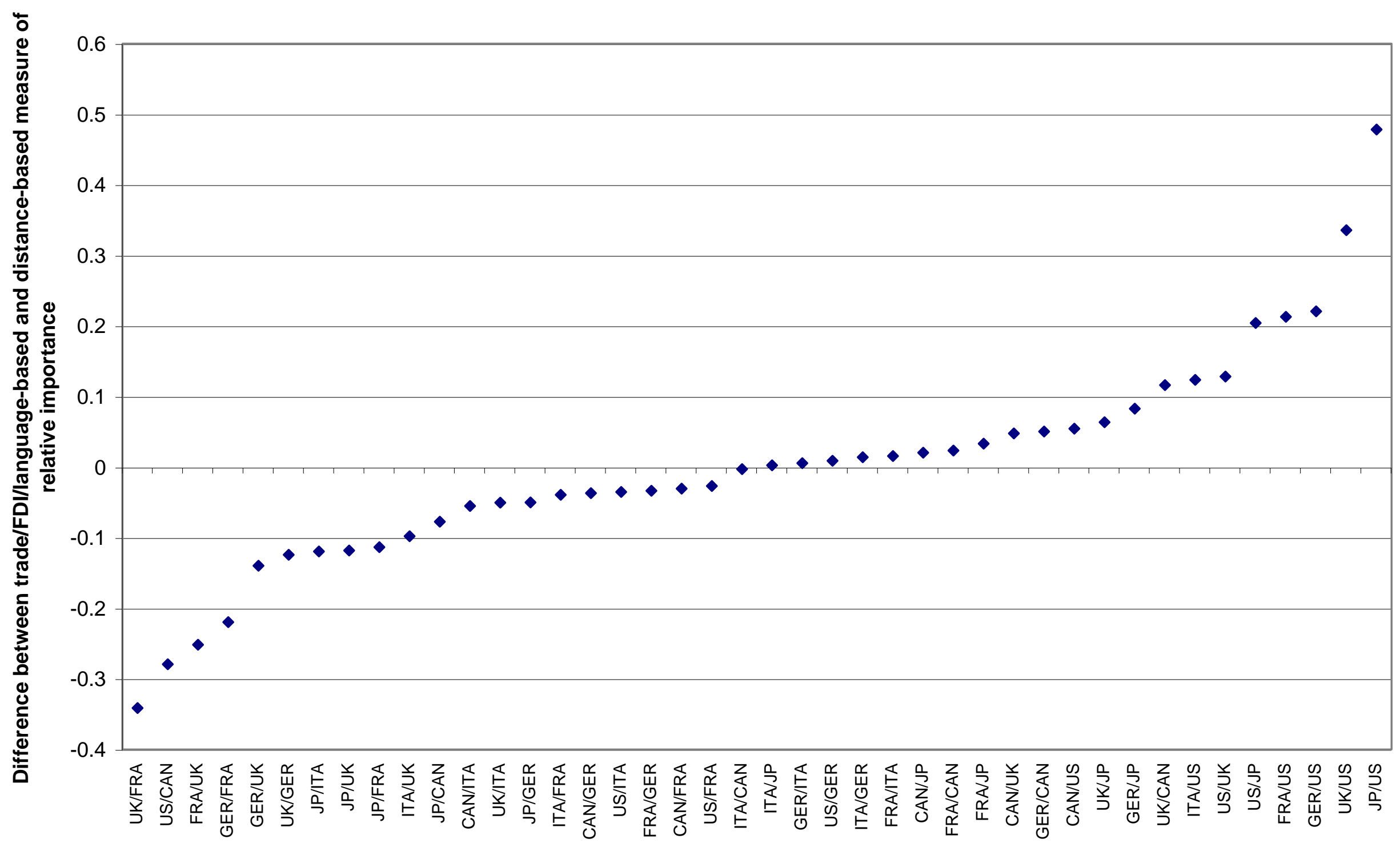




\section{References}

[1] Andrews, D. (1999), "Higher-order Improvements of a Computationally Attractive k-step Bootstrap for Extremum Estimators", Cowles Foundation Discussion Paper No. 1230, Yale University, August.

[2] Baldwin, R., and R. Forslid (2000), "The Core-Periphery Model and Endogenous Growth: Stabilising and De-Stabilising Integration", Economica 67: 307-324.

[3] Blomstrom, M., and A. Kokko (1996), "Multinational Corporations and Spillovers", CEPR Working Paper \# 1365, CEPR, London.

[4] Branstetter, L, (2001), "Are Knowledge Spillovers International or Intranational in Scope? Microeconometric Evidence from the U.S. and Japan", Journal of International Economics 53: 53-79.

[5] Caves, D. W., L. Christensen, and E. Diewert (1982a), "Multilateral Comparisons of Output, Input, and Productivity Using Superlative Index Numbers", Economic Journal 92: 73-86.

[6] Caves, D. W., L. Christensen, and E. Diewert (1982b), "The Economic Theory of Index Numbers and the Measurement of Input, Output, and Productivity", Econometrica 50: 1393-1414.

[7] Caves, R. E. (1996), Multinational Enterprise and Economic Analysis, 2nd edition, Cambridge University Press.

[8] Coe, D.T., and E. Helpman (1995), "International R\&D Spillovers", European Economic Review 39: $859-887$.

[9] Eaton, J., and S. Kortum (2000), "Trade in Capital Goods", mimeo, Boston University. 
[10] Eaton, J., and S. Kortum (1999), "International Technology Diffusion: Theory and Measurement", International Economic Review 40: 537-570.

[11] Eaton, J., and S. Kortum (1996), "Trade in Ideas: Patenting and Productivity in the OECD", Journal of International Economics 40: 251-278.

[12] Economist (2000), "Untangling E-conomics. A Survey of the New Economy", The Economist September 23, 2000.

[13] Edmond, C. (2000), "Some Panel Cointegration Models of International R\&D Spillovers", mimeo, Department of Economics, UCLA; forthcoming in Journal of Macroeconomics.

[14] EU (1999), Eurobarometer. Public Opinion in the European Union. Report No. 50, March 1999; http://europa.eu.int/en/comm/dg10/infcom/epo/eb.html

[15] Feenstra, R. (1996), "Trade and uneven growth", Journal of Development Economics 49: 229256 .

[16] Fujita, M., P. Krugman, and A. Venables (1999), The Spatial Economy: Cities, Regions and International Trade, Cambridge, MA: MIT Press.

[17] Fullerton, D., and M. Karayannis (1993), "United States", Chapter 10 in Jorgenson and Landau (1993a), pp. 333-367.

[18] Gallup, J.L., J.D. Sachs, and A.M. Mellinger (1998), "Geography and economic development", NBER Working Paper \# 6849, Cambridge, MA.

[19] Gaspar, J., and E. Glaeser (1996), "Information Technology and the Future of Cities", NBER Working Paper \# 5562, Cambridge, MA. 
[20] Greenwood, J., Z. Hercowitz, and P. Krusell (1997), "Long-run Implications of InvestmentSpecific Technological Change", American Economic Review 87: 342-362.

[21] Griffith, R., S. Redding, and J. Van Reenen (2000), "Mapping two faces of R\&D: Productivity growth in a panel of OECD industries", Institute for Fiscal Studies Working Paper \# 2000-2, London.

[22] Griliches, Z. (1995), "R\&D and Productivity: Econometric Results and Measurement Issues", in P. Stoneman (ed.), Handbook of the Economics of Innovation and Technological Change, Blackwell, Oxford, pp.52-89.

[23] Griliches, Z., and J. Mairesse (1998), "Production Functions: The Search for Identification", Chapter 6 in Econometrics and Economic Theory in the 20th Century. The Ragnar Frisch Centennial Symposium, edited by S. Strom, Cambridge University Press, pp. 169-203.

[24] Grossman, G., and E. Helpman (1991), Innovation and Growth in the World Economy, Cambridge, MA.: MIT Press.

[25] Hall, R.E. (1990), "Invariance Properties of Solow's Productivity Residual", in P. Diamond (ed.), Growth/Productivity/Employment, MIT Press, Cambridge, MA, pp.71-112.

[26] Hanson, G. (1998), "Market Potential, Increasing Returns, and Geographic Concentration", NBER Working Paper \# 6429, February.

[27] Harrigan, J. (1997), "Technology, Factor Supplies, and International Specialization: Estimating the Neoclassical Model", American Economic Review 87: 475-494.

[28] Haveman, J. (1998), Geographic Distance Data, http://intrepid.mgmt.purdue.edu/ Jon/Data/TradeData.html\#Gravity 
[29] Hulten, C. (1992), "Growth Accounting when Technical Change is Embodied in Capital", American Economic Review 82: 964-980.

[30] Jaffe, A., and M. Trajtenberg (2000), "International Knowledge Flows: Evidence from Patent Citations", Economics of Innovation and New Technology, forthcoming.

[31] Jaffe, A., M. Trajtenberg, and R. Henderson (1993), "Geographic Localization of Knowledge Spillovers as Evidenced by Patent Citations", Quarterly Journal of Economics 108: 577-598.

[32] JG (2000), "Registered Foreigners by Nationality", Table 2-15, and "Japanese Living Abroad by Country", Table 2-16, Japan Statistical Yearbook, Statistics Bureau \& Statistics Center of Japan, http://www.stat.go.jp/english/1431-02.htm

[33] Jorgenson, D.W. (1993), "Introduction and Summary", Chapter 1 in Jorgenson and Landau (1993a), pp.1-56.

[34] Jorgenson, D.W., and R. Landau (1993a), Tax Reform and the Cost of Capital, (eds.), The Brookings Institution, Washington, D.C.

[35] Jorgenson, D.W., and R. Landau (1993b), "Appendix" in Jorgenson and Landau (1993a), pp.369-406.

[36] Keller, W. (2000a), "Do Trade Patterns and Technology Flows Affect Productivity Growth?", World Bank Economic Review 14: 17-47.

[37] Keller, W. (2000b), "Geographic Localization of International Technology Diffusion", NBER Working Paper \# 7509, Cambridge, MA.

[38] Keller, W. (1998), "Are International R\&D Spillovers Trade-related? Analyzing Spillovers Among Randomly Matched Trade Partners", European Economic Review 42: 1469-1481. 
[39] Leamer, E., and J. Levinsohn (1995), "International Trade Theory: The Evidence", in G.M. Grossman and K. Rogoff (eds.), Handbook of International Economics, Vol.3, Elsevier, Amsterdam.

[40] McKinsey (2000), Why the Japanese economy is not growing: micro barriers to productivity growth, McKinsey Global Institute, Washington, D.C., July 2000.

[41] OECD (1999a), STAN Database for Industrial Analysis, OECD, Paris, various years.

[42] OECD (1999b), OECD Employment Outlook, OECD, Paris, various years.

[43] OECD (1999c), Activities of Foreign Affiliates, OECD, Paris, 1999.

[44] OECD (1998), ANBERD. Basic Science and Technology Statistics, various years, OECD, Paris.

[45] Pilat, D. (1996), "Competition, Productivity, and Efficiency", OECD Economic Studies 27: $107-146$.

[46] Redding, S., and A. Venables (2000), "Economic geography and international inequality", working paper, London School of Economics, September.

[47] Samuelson, P. (1954), "The Transfer Problem and Transport Costs, II: Analysis of Effects of Trade Impediments", Economic Journal 64: 264-289.

[48] Scarpetta, S., A. Bassanini, D. Pilat, and P. Schreyer (2000), "Economic Growth in the OECD Area: Recent Trends at the Aggregate and Sectoral Level", OECD Economics Department Working Paper \# 248.

[49] Scherer, F. (1984), "Using Linked Patent and R\&D Data to Measure Interindustry Technology Flows", in Z. Griliches (ed.), RESD, Patents, and Productivity, The University of Chicago Press for NBER, pp.417-461. 
[50] Sjöholm, F. (1996), "International transfer of knowledge: The role of international trade and geographic proximity", Weltwirtschaftliches Archiv 132: 97-115.

[51] StatCan (2000), "Population Able to Speak Various Languages", Table 6_7.IVT, 1996 Population Census, unpublished material.

[52] Trefler, D. (1995), "The Case of the Missing Trade and other Mysteries", American Economic Review 85: 1029-1046.

[53] West, A., A. Edge, and E. Stokes (2000), "Examination and assessment of data on foreign language learning", final report, Centre for Educational Research, London School of Economics and Political Science, May 2000. 


\section{A Data on R\&D Expenditures}

The R\&D expenditure data comes from OECD (1998). The data is in part estimated, because not all countries conduct an annual R\&D survey. I rely on the OECD estimates of missing R\&D expenditure data, which have been prepared using cubic spline interpolation techniques. The OECD (1998) publication covers the years 1973-97; estimates for 1970-72 are based on data in hardcopy versions of the OECD's Basic Science and Technology Statistics. Expenditures qualify as R\&D according to the OECD's Frascati Manual definition.

R\&D stocks are derived from expenditure data on total business enterprise intramural R\&D $\left(\right.$ denoted $\left.E_{c i t}\right),{ }^{37}$ which is available in constant 1990 \$ U.S. using the OECD purchasing power parity rates for conversion. I use the perpetual inventory method to construct stocks, assuming that

$$
\begin{array}{ccc}
S_{t} & =\left(1-\delta^{R}\right) S_{t-1}+E_{t-1}, \text { for } t=1971, \ldots, 1995 \\
& \text { and } \\
S_{1970} & = & \frac{E_{1970}}{\left(g^{R D}+\delta^{R}\right)}
\end{array}
$$

where the industry and country subscripts have been suppressed. The rate of depreciation of the R\&D stock, $\delta^{R}$, is set at 0.1 , and $g^{R D}$ is the average annual growth rate of $S$ over the period of 1970 1995. I have experimented with estimating the same specifications based on R\&D data constructed with other plausible values for $\delta^{R}$. These results are similar to what is reported above.

\footnotetext{
${ }^{37}$ The exception is Italy, where also extramural R\&D expenditure is covered. The OECD code for this series is BERD
} 


\section{B Data on labor inputs, physical capital, value added and gross production}

The OECD (1999a) STAN database and Pilat (1996) are the sources for these variables. The former provides internationally comparable data on economic activity at the industry level for OECD countries. The TFP index construction uses data on labor, physical capital, labor compensation and industry deflators, together with value added and gross output data as output measures. The number of workers variable is taken from the STAN database. This includes employees as well as the self-employed, owner proprietors and unpaid family workers. These figures are adjusted by the average annual hours per manufacturing worker in country $c$ and time $t$ to arrive at the labor input measure, denoted $L$. The data on annual hours worked is from OECD (1999b); a relatively small number of missing values has been interpolated.

The STAN database contains values on gross fixed capital formation in current prices, which I use to construct industry-level capital stocks. First, the investment flows are converted into constant 1990 prices using country- and industry-specific deflators that are derived from series of value added in constant and current prices (in the STAN database). Second, the perpetual inventory method is used to estimate the capital stocks, with

$$
\begin{array}{ccc}
\tilde{K}_{c t} & =\left(1-\delta^{k}\right) \tilde{K}_{c t-1}+i n v_{c t-1}, \text { for } t=1971, \ldots, 1995, c=1, \ldots, 7 . \\
& \text { and } \\
\tilde{K}_{c 1970}= & \frac{i n v_{i 1}}{\left(g_{i}+\delta^{k}\right)}, c=1, \ldots, 7,
\end{array}
$$

where industry subscripts have been suppressed. The variable $i n v$ is gross fixed capital formation in constant prices (land, buildings, machinery and equipment), $g$ is the average annual growth rate of

inv over the period $1970-1995$, and $\delta^{k}$ is the rate of depreciation for capital, which I have estimated to 
be $10 \%$. The capital measures are adjusted for cyclical effects in capacity utilization by estimating a smoothed gross output series $\ln \widehat{\tilde{Z}}_{c i t}$ (from the regression $\left.\ln \tilde{Z}_{c i t}=\partial_{c i}+\zeta_{t}+\varphi_{c i t}\right)$, and then forming 38

$$
K_{c i t}=\tilde{K}_{c i t} *\left(1+\left(\widehat{\ln }_{c i t}-\ln \tilde{Z}_{c i t}\right)\right), \forall c, i, t
$$

With the labor and capital input variables in hand, let the parameter $\alpha$ be the share of the labor in total production costs. Following the approach suggested by Hall (1990), the $\alpha$ 's are not calculated as the ratio of total labor compensation to value added (the revenue-based factor shares), but as cost-based factor shares which are robust in the presence of imperfect competition. For this the framework of the integrated capital taxation model of King and Fullerton (see Jorgenson 1993, Fullerton and Karayannis 1993) and data provided in Jorgenson and Landau (1993b) has been used. ${ }^{39}$

Having obtained the series on the user cost of capital and capital stock data, $\alpha$ is given by

$$
\alpha=\frac{w L}{w L+p K}
$$

where $w L$ are the constant price labor costs. Labor and capital inputs together with the factor shares allow to construct an index of relative total inputs $\ln I_{c i t}-\overline{\operatorname{lnI}}_{c i t}$,

$$
\ln I_{c i t}-\overline{\operatorname{lnI}}_{c i t}=\frac{1}{2} *\left[\alpha_{c i t}+\bar{\alpha}_{i t}\right]\left[\ln L_{c i t}-\overline{\ln }_{i t}\right]+\frac{1}{2} *\left[\left(1-\alpha_{c i t}\right)+\left(1-\bar{\alpha}_{i t}\right)\right]\left[\ln K_{c i t}-\overline{\ln }_{i t}\right],
$$

\footnotetext{
${ }^{38} \mathrm{I}$ impose a maximum absolute value on the adjustment term $\Theta_{c i t}=\left(\widehat{\ln }_{\text {cit }}-\ln \tilde{Z}_{c i t}\right)$, mainly to avoid negative capital stock estimates: when $\left(\widehat{\ln }_{c i t}-\ln \tilde{Z}_{c i t}\right)>0.8$, I set $\Theta_{c i t}=0.8$, and when $\left(\widehat{\ln \tilde{Z}_{c i t}}-\ln \tilde{Z}_{c i t}\right)<-0.8$, I set $\Theta_{\text {cit }}=-0.8$.

${ }^{39}$ The effective marginal corporate tax rate $\omega$ is given by the wedge between before-tax $(p)$ and after-tax rate of return $(\bar{\rho})$, relative to the former: $\omega=\frac{p-\bar{\rho}}{p}$. The variable $p$ is the user cost of capital. It is a function of the statutory marginal tax rate on corporate income, available investment tax credits, the rates of depreciation, and other determinants. In the case of equity financing, the after-tax rate of return will be $\bar{\rho}=r+\pi$, where $r$ is the real interest rate and $\pi$ is the rate of inflation. Jorgenson (1993) tabulates the values for the marginal effective corporate tax rate in Table 1-1. According to the "fixed-r" strategy, one gives as an input a real interest rate $r$ and deduces the tax rate. In this case, I use a value of $r=0.1$, which, together with the actual values of $\pi$ allows, using the relationship $\omega=\frac{p-\bar{\rho}}{p}$, to infer the user cost of capital, $p$. From Jorgenson's Table 1-1 on $\omega$, I use the values on "manufacturing" (the 1980 values given are used for 1970-1982 in the sample, the 1985 values for 1983-1986, and Jorgenson's 1990 values are used for 1987-1991).
} 
for all $c, i$, and $t$, where $\overline{\ln }_{i t}=\frac{1}{C} \sum_{c} \ln L_{c i t}, \overline{\ln }_{i t}=\frac{1}{C} \sum_{c} \ln K_{c i t}$, and $\bar{\alpha}_{i t}=\frac{1}{C} \sum_{c} \alpha_{c i t}$. The relative TFP index is obtained by subtracting relative total input from relative output, see equation (1) in the text.

I use two alternative sets of exchange rates to convert the countries' output series (generally, this is value added, but gross output is used for specification 4.2) into the same currency: industryspecific PPP exchange rates based on Pilat (1996) and all-manufacturing PPP exchange rates from the STAN database, OECD (1999a). Because Italy is not covered in Pilat's paper, I have estimated the Italian industry-specific PPP rates as an average of those of France, the U.K., and Germany (the other three European countries in the sample).

A more general TFP index which allows for increasing returns to scale is employed to investigate the robustness of the results. It is based on work by Caves, Christensen, and Diewert (1982b):

$$
\ln \check{F}_{c i t}=\ln F_{c i t}+(1-\epsilon) \bar{\sigma}_{c i t}\left(\ln L_{c i t}-\overline{\ln L_{i t}}\right)+(1-\epsilon)\left(1-\bar{\sigma}_{c i t}\right)\left(\ln K_{c i t}-\overline{\ln K_{i t}}\right), \forall c, i, t
$$

where $\ln F_{c i t}$ is the relative TFP index defined in equation (1) and $\epsilon$ is an indicator of the returns to scale. With $\epsilon=1$, production is characterized by constant returns to scale, while increasing returns to scale are present whenever $\epsilon>1$ : for given levels of outputs and inputs, productivity is lower if there are scale economies than with constant returns. To examine the robustness of the analysis, the results of assuming a relatively small degree of increasing returns $(\epsilon=1.05)$ are presented in Table 4 . 